Illinois State University

ISU ReD: Research and eData

Theses and Dissertations

2-27-2016

\title{
Progress as a Student Teacher: An Autoethnography
}

Adrielle J. Schneider

Illinois State University, ajschneid25@gmail.com

Follow this and additional works at: https://ir.library.illinoisstate.edu/etd

Part of the Art Education Commons, and the Teacher Education and Professional Development Commons

\section{Recommended Citation}

Schneider, Adrielle J., "Progress as a Student Teacher: An Autoethnography" (2016). Theses and Dissertations. 598.

https://ir.library.illinoisstate.edu/etd/598

This Thesis is brought to you for free and open access by ISU ReD: Research and eData. It has been accepted for inclusion in Theses and Dissertations by an authorized administrator of ISU ReD: Research and eData. For more information, please contact ISUReD@ilstu.edu. 


\title{
PROGRESS AS A STUDENT TEACHER:
}

\section{AN AUTOETHNOGRAPHY}

\author{
Adrielle J. Schneider
}

\section{Pages}

This autoethnographic action-research study was developed over an eight-week student teaching placement at a junior high school in Central Illinois. The participants in the study included my cooperating teacher and university supervisor as well as students in sixth, seventh, and eighth grade art classes. The purpose of this study was to discover how I developed as a classroom art teacher during an eighth-week student teaching placement and to analyze the successes and failures of my teaching methods used during my student teaching placement, which included student centered teaching, the use of visual process diaries, allowing and encouraging mistakes, integrating diverse and contemporary artists, and the use of positive reinforcement. This study revealed the success and failures of each method used as well as the limitations and time constraints that took place during student teaching. Using while using studentcentered teaching techniques, positive reinforcement, arts-based educational research, and allowing and encouraging mistakes were successfully implemented teaching methods. The use of visual process diaries and the 
attempt to incorporate diverse artists were less than successful due to time constraints. The study also recommends that student teachers use their placements as a way to experiment with any methods and lessons they would like to use in future teaching.

KEYWORDS: Art Education, Autoethnography, Positive Reinforcement, Student Centered Teaching, Student Teaching, Visual Process Diaries 
PROGRESS AS A STUDENT TEACHER:

AN AUTOETHNOGRAPHY

ADRIELLE J. SCHNEIDER

A Thesis Submitted in Partial Fulfillment of the Requirements for the Degree of

MASTER OF SCIENCE

School of Art

ILLINOIS STATE UNIVERSITY

2016 
(C) 2016 Adrielle J. Schneider 


\section{PROGRESS AS A STUDENT TEACHER:}

AN AUTOETHNOGRAPHY

ADRIELLE J. SCHNEIDER

COMMITTEE MEMBERS:

Judith Briggs, Co-Chair

Edward Stewart, Co-Chair 


\section{ACKNOWLEDGMENTS}

This thesis is dedicated to my number one fan, my Dad. Without his support I would not have found the courage to continue my education. I want to thank my sister Hana who, also with a background in education, helped me discover my teaching self and my brother, Jude, who possibly without knowing it taught me the importance of critical thinking and how to embrace learning as a lifelong process. Finally I want to thank my love, Lane, for always being there and helping me through my most difficult moments.

A. J.S. 


\section{CONTENTS}

Page

ACKNOWLEDGMENTS

CONTENTS

CHAPTER

$\begin{array}{ll}\text { I. INTRODUCTION } & 1\end{array}$

The Problem 3

Purpose for the Study

Need for the Study $\quad 6$

Research Questions $\quad 8$

Definition of Terms $\quad 9$

$\begin{array}{ll}\text { II. REVIEW OF LITERATURE } & 10\end{array}$

General Literature Review 10

Student-Centered Teaching 10

Allow and Encourage Mistakes 14

Arts-Based Educational Research 16

Importance of Visual Process Diaries $\quad 19$

Integrating Diverse and Contemporary Artists 21

Need for Reflection 23

Positive Reinforcement 25

III. METHODOLODY 26

Action Research and Autoethnography 26

Data Collection and Analysis $\quad 28$

Participants $\quad 29$

Limitations $\quad 30$

Summary $\quad 30$

$\begin{array}{ll}\text { IV. ANALYSIS } & 33\end{array}$

$\begin{array}{ll}\text { Analysis Background } & 33\end{array}$ 
The Frames $\quad 33$

Curriculum Creation $\quad 39$

Developing My Unit $\quad 41$

$\begin{array}{lr}\text { Teaching } & 49\end{array}$

Day 1

Day $2 \quad 55$

Day $3 \quad 57$

Day $4 \quad 58$

Day 5

Day $6 \quad 61$

Day $7 / 8 \quad 62$

Day $9 \quad 63$

Days 10-12 66

Day $13 \quad 66$

$\begin{array}{ll}\text { Discipline } & 67\end{array}$

Sixth Grade and Positive Reinforcement 69

Eighth Grade and Positive Reinforcement $\quad 72$

$\begin{array}{ll}\text { The Clay Room } & 73\end{array}$

$\begin{array}{ll}\text { Student Work } & 76\end{array}$

$\begin{array}{ll}\text { Summary } & 78\end{array}$

V. DISCUSSION AND RECCOMENDATIONS 80

Development $\quad 80$

Successes and Failures $\quad 83$

Student-Centered Teaching 84

Allow and Encourage Mistakes $\quad 86$

Arts-Based Educational Research $\quad 87$

Visual Process Diaries $\quad 88$

Integration of Diverse and Contemporary Artists $\quad 90$

Positive Reinforcement $\quad 91$

Recommendations for My Own Teaching 92

Recommendations for Future Student Teachers 93

Recommendations for Future Study $\quad 95$

$\begin{array}{ll}\text { REFERENCES } & 96\end{array}$

$\begin{array}{ll}\text { APPENDIX A: Letter of Assent } & 105\end{array}$

$\begin{array}{ll}\text { APPENDIX B: Letter of Consent } & 107\end{array}$ 
APPENDIX C: Idioms Packet

APPENDIX D: Student Work 


\section{CHAPTER I}

\section{INTRODUCTION}

One afternoon in my undergraduate art education course, a visitor shared with the class the ins and outs of a professional interview. She touched on everything from choosing an outfit and covering tattoos to how to prepare for answering difficult questions. While she gave examples of a variety of questions, there was one that has haunted me ever since: Are you first an artist or a teacher? I thought the answer was simple because creating has been a part of me since I can remember and "artist" was always in my description. However, my path has shifted, and through my graduate experiences I discovered a passion for education I had never expected to know.

When I decided to go back to school and learn the art of teaching, I laughed at myself and the memory of an old teacher explaining how instructing students was never in his original plans. He wanted to be a rock star and made sure his teachers knew he would never end up working at a school. Being a hormonal and bratty pre-teen, I raised my hand, chuckled and said, "I know that I will never be a teacher." I suppose I should have listened when he tried to teach us to "never say never;" however at the time, being an artist and teaching were not in the same category. 
It wasn't until recently that I found some very important commonalties between the two careers, besides being able to think outside the box. As an artist, it has become natural to evaluate my work and creative process while welcoming peer criticism to examine the various ways my work is perceived. While learning to become an educator, I discovered the similarities between artistic reflection and reflection of teaching practices. In both professions it is essential to understand my own perspective as well as the perspective of those around me. McConnell (2010) has stated that self-reflection is critical to growth in a profession because a person cannot move forward until she has an awareness of where she currently stands. This process is extremely important for educators and artists who are involved in professions that are constantly changing.

While the practice of self-reflection is important, artists and educators also need to be able to accept feedback. Artists learn to take constructive criticism from mentors, peers, and even friends; while teachers must learn to take feedback from mentors, colleagues, and even students. Mentors work to guide those in both professions, and peers or faculty members can offer support to someone in a similar situation. Teachers must also receive feedback from students because it creates an environment that involves accountability and trust between the students and the teacher (Johnson, 2009). The students also provide insight for the teacher because they can explain what they need, whether they are confused and can sometimes explain what created the confusion. They can even express the successful portions of their learning experience. 
While addressing similarities between self-reflection and growth in both careers, I tried again to answer that question. Am I first an artist or a teacher? While I truly believe I was born an artist, I also think it was the first step into my career as a teacher. Being an artist taught me how to think creatively, reflect on my work and accept constructive criticism from others. Maybe at the end of the day there is no "first" for me but instead a combination of two careers that work together. Now that I know how to learn from feedback and reflect as an artist, I can transition this ability into my experiences as a teacher.

\section{The Problem}

At what point does a student transition into a teacher? Is it the moment they first address a class or when they receive their teaching license? While developing into the type of educator I want to be, I have learned about diverse methods, techniques, and strategies that can be used in the classroom. Some teachers may take a more essentialist or traditional approach meaning they believe the school's purpose is to teach a rigid curriculum that instills students with the ability to become moral citizens through things like respecting authority and fidelity (Shaw, n.d.). Others might choose a more progressive philosophy, which follows a curriculum that focuses on what is relevant to students, like experiences, interests, and abilities (Bain,2004; Ladson-Billings,1994). I, along with other future educators, make decisions based on information I have learned in my courses and what I have witnessed during clinical experiences where I had the opportunity to observe teachers and interact with students. 
The problem with the journey of developing into a teacher is the transition between student and educator. As a student I spent a lot of time reading, researching, and listening to the experiences of my professors in an attempt to become a great educator. My program also did a fantastic job integrating clinical experiences that allowed me to taste different parts of the world of education through hands-on involvement and reflection. According to the National Art Education Association (NAEA, 2014), hands-on involvement through clinical experiences is extremely important because teaching is a "practice skill" or a skill that cannot be learned just through courses or researching various theories.

While reflection was a large part of my coursework, my writings were based on minimal interactions with students and instruction in short periods. This provided a small window into the potential of the methods and techniques I had researched as well as my overall abilities as a teacher, because the day-to-day planning, instruction, grading, and other components of teaching were impossible to integrate into regular coursework. Without taking part in these teaching experiences, I was limited to only reflecting on flashes of a teacher's experiences rather than on the everyday. Danielson (2009) argues that in order for a teacher to engage thoughtfully about her progress, the teacher must reflect on the difficult choices that are made every single day. For this reason, developing this study in order to reflect consistently over my student-teaching placement became an essential part of my journey as a future educator. 


\section{Purpose for the Study}

The intention for this autoethnographic action research was to spend time doing self-reflection on my teaching methods throughout my student teaching experience at a junior high and invite criticism and feedback from my mentor teachers and students. By using autoethnography, a method of writing that uses the perspective of the writer to create a detailed version of their experience (Anderson, 2014), I was able to reflect on personal teaching strengths and weaknesses through observation and the feedback of others. Autoethnography will provide the audience with a more personal look into what I experienced during my placement in order to create a better understanding of the different responsibilities of student teachers. This reflective process will also guide future decisions in my own classroom and teach me how to create a dialog with students and colleagues to gain a better awareness of what they need in order to be successful.

While student teaching alone is a great way to gain experience in a classroom environment, reflection is necessary in order to fully engage with such involvement (Dewey, 1916). Dewey argues that people have various experiences but without thought, those experiences are essentially meaningless and one cannot examine the details or links between actions and consequences. Without reflection, I would not have been able to understand why a lesson was successful or unsuccessful which would have prevented me from making necessary changes of my teaching methods and inhibit my success as a future educator as well as the achievement of my future students. 
Osterman (1990) also argues for the importance of self-reflection in education. She describes reflection as a challenging process that pushes for critical analysis of personal choices and behaviors in order to develop their craft. By taking part in reflective practice, teachers are able to review what actually happened in comparison to what was expected. As a student teacher I had many expectations for lessons, student achievement, and other aspects of teaching that didn't necessarily go as planned.

\section{Need for the Study}

While other educators have written reflections on their teaching experiences, each author has a different purpose. Vasconcelos (2011), an alumnus of the University of Georgia, developed her thesis around personal reflections and memories to understand the teacher she was at the time and how she became that way. She reflected on her previous education as well the evolution of her experiences of being a teacher and a learner. She discovered her most important moments happened when having discussions with her teachers and her students, which changed her pedagogy to focus on building relationships. Although her interest in this type of research was for a personal journey, she also had hopes for her research to be of relevance to other educators and students. Even though others will be able to relate to her story in various ways, the overall experience will always be a reflection of her perspective and understanding of self.

My personal desire to discover who I truly am as an art educator and how and whether my believed methods will come to life in a classroom environment 
reflects the action research that art educators unknowingly conduct each day in the classroom (Klein, 2014). According to Klein, action research is a type of field study in which reflection is used to develop personal theories and make future changes or take action in regard to teaching practices. Taking part in action research can be especially important for those who are transitioning from student-teaching to professional practice, because they have the opportunity to see first-hand, what the profession will be like. Klein also argues that this type of research can reveal discoveries of new ideas for how to teach art. Educators are able to look at their abilities in a critical manner and find ways to make improvements.

While student teaching is a requirement for the education program, completing this experience is an essential part of the development of a future educator. Savage, Cannon, and Sutters (2015) write, "While classroom instruction, textbooks, and assignments serve important functions in our students development, we believe spending time in an art classroom with an art teacher is the most authentic learning opportunity teacher preparation programs offer" ( $p$. 22). They continue by explaining how working with a cooperating teacher gives student teachers the experience of handling the day-to-day responsibilities of teaching. From organization to long weekend hours, student teachers can start developing good teaching practices and learn the methods used by their cooperating teacher. Schank (1995) explains that, as with any other way of understanding, whether painting a picture or completing a math problem, one 
must have the hands-on experience with the help of a mentor in order to fully understand the demands of teaching.

A great deal is written from the perspective of experienced art educators like Eldridge (2012), who explores the complexities of teaching at an elementary school and defends a curriculum based on social justice and visual culture theory, or like Alexenberg (2008), who creates a narrative about realms of learning in a post-digital age. However, little research could be found from the perspective of the student teacher. Considering student teaching is an essential part of becoming a teacher, it is important to reflect on this part of the process. Providing the perspective of a student teacher can help future teachers, their professors, and cooperating teachers understand what the student is going through. While instructors experienced student teaching at some point prior to their current careers, the teaching practice evolves over time. Showing the perspective of a current student teacher will help professors and cooperating teachers stay in touch with the current processes. This will give them the knowledge to provide the best support possible while students take part in student teaching.

\section{Research Questions}

To help guide this study the following research question was developed: In what ways did I develop as a classroom art teacher during an eight-week junior high school student-teaching placement?

Sub questions included:

- What teaching methods were successful/unsuccessful? Why? 
-What changes could I make in my future classroom to help me and my students become more successful?

\section{Definition of Terms}

Action Research- Field research which includes reflection that can be analyzed with the goal for changes in future practice (Klein, 2014).

Autoethnography- A writing method that uses the perspective of the writer to give the audience an inside look at an event or idea (Anderson, 2014).

Active Learning- This is a process in which students solve problems, answer questions, ask questions, debate, discuss, and explain during class (Felder, n.d.).

Contemporary Art- Contemporary art is the art of today, produced by artists who are currently alive (Contemporary art, 2016).

Multicultural Education- refers to any form of education or teaching that incorporates the histories, texts, values, beliefs, and perspectives of people from different cultural backgrounds (Hidalgo, 2012).

Process Diary- A journal used as a tool in teaching and learning to record ideas, experiments, mistakes, and processes for a final work of art. This will generally include photographs, sketches, paintings, reflections, and notes (Board of Studies NSW, 2003).

Student Centered Teaching- A teaching method that changes the focus of instruction from the teacher to the student (Felder, n.d). The student becomes more actively involved in what and how they learn. This method often integrates active learning, cooperative learning, and focus on student interests. 


\section{CHAPTER II}

\section{REVIEW OF LITERATURE}

\section{General Literature Review}

The following review of literature provides insight into the current teaching methods and techniques that I used during my study. These methods included student centered teaching, allowing and encouraging mistakes, arts-based research, process diaries, integration of diverse and contemporary artists, positive reinforcement, and the importance of self-reflection. The literature review also provides a background on the methodology of this study and other studies that were found that related to this study.

\section{Student-Centered Teaching}

Figures throughout history including John Dewey, Jean Piaget, and Howard Gardner have argued for a student-centered teaching environment where the learning becomes less about what the teacher chooses and more about what the students want to learn (Cubukcu, 2012). This approach has been known to improve essential skills, such as critical thinking, problem solving, and reflective thinking because the students become engaged in the learning process. Learning shifts from what was once irrelevant to something more meaningful because the students are able to make some of their own choices. 
According to Brandt (1987), Gardner contributes to the literature by advocating both the necessity of student-centered teaching and the importance of art education. He is passionate about student interest in the classroom and discusses how American Schools are truly struggling in this area. Gardner explains," What we need in America is for students to get more deeply interested in things, more involved in them, more engaged in wanting to know" (Brandt, 1987, p.33). He continues by explaining how the arts are a good place to make this engagement happen for students, because the lack of interest by administrators provides art teachers with the opportunity to take chances and explore methods that normally wouldn't be accepted.

William James was also a supporter of child-centered psychology (Pajares, 2003). James believed teachers needed to be aware of the interests and needs of their students in order to adjust their instruction accordingly and make a more effective teaching environment. He argued that students could become engaged with material that is less intriguing by linking it to the things that they already enjoyed. James even presented steps that teachers could take in order to integrate this process. The first step for a teacher would be to pay attention to the student's interests and needs. The teacher should then gather their students' prior knowledge on the topic to be taught and present the topic in a direct and clear way. Finally, the teacher should link new knowledge with the students' interests. Ideally, this would create the opportunity for students to engage with the material by connecting new material to what the students already believed was relevant to their lives. 
Allowing the student to bring in a personal perspective is especially important in the arts. Garion (2002) argues that the arts are a place where students' identities and academics can come together. He believes that the only way for these identities to develop in the art room is when artwork begins with the student rather than with the teacher. When the stereotypical hand turkey or other make-and-take projects are introduced, students have no connection to their learning process because what they make is not relevant to their personal lives. He continues by explaining the importance of creating opportunities for students to integrate their own cultural backgrounds, as this can become not only a great source for their artwork but also a great support for intellectual development.

The student-centered teaching approach also allows more opportunity for creativity, which directly affects brain function. According to neuroscientists interested in creative thinking, parts of the brain that normally do not communicate, do so when thinking creatively (Pilecki \& Sousa, 2013). Brain scans have revealed more areas of stimulation when working on creative projects specifically when it comes to regions involved in working memory, emotion, and cognition. Studies also revealed that the only way to be creative is to work in a creative environment that allows experimentation or improvisation. When effectively using a student-centered approach, students are able to think more freely because they are pulling from personal experiences rather than following strict step-by-step instructions (Hurwitz \& Day, 2007).

One major part of student-centered teaching includes active learning where students are challenged to answer questions, develop their own 
questions, debate, discuss, and brainstorm. Bain (2004) argues that the involvement of questioning is crucial to learning. Rather than giving students information to memorize, they need to be able to ask questions in order to further develop knowledge. While it is important for the teacher to develop questions that will guide students through the curriculum, it is also essential to allow room for students to come up with questions on their own. Any question asked however, must be something the student cares about answering. Bain argues that without questions of interest, students will not care to answer them and will ignore the bits of information that help them learn.

Many teachers (Andrews, 2010; Gude, 2013; Marzano \& Toth, 2016) agree that student-centered teaching is a great approach to use in any art classroom. In an attempt to discover what it means to be an effective teacher, the National Education Association (NEA) did research involving 21 different educators throughout the United States (The Future of Teaching, 2014). One focus in the study was for the teachers to develop a future vision of education and teacher effectiveness. These educators collectively agreed that the studentcentered approach is a necessary part of effective teaching because it, "leads to improved student outcomes in clear and demonstrable ways" (p.16).

While there are many supporters of this approach, student-centered teaching is not happening as much as it should be. Strickland (2012) explained that students in American classrooms are likely to be a part of a system ruled by administrators and teachers; however, she argues that students "need to be a part of their educational journey and take responsibility for choices made" (p.12). 
The lack of student involvement can be especially difficult for at-risk students who already struggle to stay interested and motivated enough to attend class. When the lessons are not relevant to these student's lives, they become robots who simply go through the motions of learning rather than gaining knowledge and applying it elsewhere (Strickland, 2012).

\section{Allow and Encourage Mistakes}

Starting at a young age, some students believe their intelligence is fixed and in order to avoid embarrassment they sidestep specific activities only to focus on those that will show off their perceived strengths (Dweck, 2007). Other students however, focus less on how smart they are and instead believe if they work hard enough, they can succeed. These two notions come from either a fixed mindset where students worry about being labeled either smart or not smart or a growth mindset where students are interested in making an effort to learn and are willing to make mistakes through that process. Psychologist Carol Dweck spent years studying children in their classroom environments in order to figure out the cause for these differentiations.

Dweck (2007) discovered the problem came with the way students were praised. Essentially, those praised for intelligence displayed a fixed mindset while those praised for effort had a more open growth mindset. The students with a fixed mindset also had the tendency to ask for easier tasks, while the growth mindset students wanted a challenge. Overall, Dweck argued that teachers should be aware of the type of praise they hand their students. Rather than handing out compliments simply for their right answer, teachers should praise the 
efforts of achievement that are made by their students. She stated, "It's time for us to adopt a growth mind-set and learn from our mistakes. It's time to deliver interventions that will truly boost students' motivation, resilience, and learning" ( $p$. 35).

The integration of growth-mindset practices can be especially important when working with students in poverty. Jensen (2013) explains how students in poverty not only have trouble with classroom engagement due to factors including poor health and nutrition but they also have a tendency to lack effort. Students in a low socioeconomic setting tend to believe it's not worth trying if failure is highly likely. By incorporating a growth mindset environment where students are praised for effort and develop an understanding that their brains can change, students will become more hopeful and see possibilities for strengthening their abilities.

Actor and writer John Cleese is also an advocate for positive attitudes regarding making mistakes (Jones, 2016). In a speech he argued that mistakes must have a more positive response and be embraced as a learning opportunity. He describes right and wrong as being "fuzzy concepts," ( $(\mathbb{1})$ rather than absolute and argues that our world is not made up of binaries, but, instead, is filled with "fuzziness and near misses of all kinds" (ף 1). He continues by explaining how each mistake can be corrected, and when we make mistakes it is an opportunity to be given feedback, make adjustments, and continue until we hit the appropriate path or find the best answer. 
According to Hurwitz \& Day (2007) the art classroom is already at an advantage for encouraging mistakes because of the nature of art. It is about experimentation, exploration, creativity, and open mindedness. Eisner (2013) adds to this argument by explaining how art is not about doing an equation to get the right answer; its exploring ways to find multiple, and sometimes unpredictable, answers. Jensen (2001) describes the arts as a performance over time, rather than a desire for immediate results. He explains that the arts "require an environment of discovery that can rekindle the love of learning" (p.12).

Many teachers believe that their routine should be to pick out good students, instruct for meaning, provide answers through lectures or other oral explanations, and assess student response (Bain, 2004). The best teachers however, explore ways to help all of their students and allow time for them to work through problems. The best teachers provide environments where students aren't afraid to think aloud and make mistakes, because the students have multiple opportunities to work and receive feedback before the final grading happens. In order to provide these opportunities, teachers must ask questions like "Will I have time to talk with students individually in addition to reading their work? [and] Can I use class time for students to work on problems in groups and then offer them collective feedback?" (p.58).

\section{Arts-Based Educational Research}

According to Greenwood (2012) arts-based educational research (ABER) has become more popular recently due to its growing success in education and other fields. Part of this success can be attributed to the nature of art, which 
allows the audience to engage with processes and experiences not applicable to traditional research methods. Greenwood describes ABER as having two dominant approaches. The first approach uses the arts to study alternative topics such as social and educational issues. This approach is also commonly used to observe cultural attributes and concerns of identity. The second approach allows the arts to be the main topic of study while discovering various layers of content within an artwork.

While the first approach, according to Greenwood (2012), tends to be more popular with $A B E R$, I find myself using both methods when creating unit plans. For this particular study, I used the second approach by attempting to guide students to uncover meaning in the artwork I presented by exploring size, material, and visual representations. Since the artworks presented to the students were ceramic masks that incorporated layers of the artist's identity, the first approach was easily integrated as a way for students to connect personal memories into their mask making to discover events that contributed to their identities.

According to Barone and Eisner (2012) ABER also provides opportunity to enrich perspectives rather than argue for certainty. In other words, the goal for ABER is to have students ask questions searching for correct answers. In order to accomplish this goal, arts-based researchers tend to follow a specific design. Barone and Eisner describe the first part of this design as the format, which follows a much less conventional approach than traditional research. Researchers using this method often work more freely with their format and 
experiment in order to find the most productive way to inspire the readers to discover their own questions. This means they integrate a variety of types of text from poetry and critical essays to plays and biographies.

The second part of the design according to Barone and Eisner (2012) is language. The language used by these researchers is comparable to other suggestive writings, including storytellers, poets and art critics. By creating this metaphorical experience, the readers are able to make decisions about the information rather than provide closed statements or observations, which will essentially offer the readers the ability to ask more questions. Arts-based researchers also incorporate descriptive writing instead of using completely theoretical approaches. This gives readers a better understanding of specific and unique events.

As researchers follow this design for their writing they are able, in a sense, to create virtual realities. Barone and Eisner (2012) point out that this provides a look into activities and perspectives that readers may not be able to see otherwise and "entails entering a new particular psychological landscape" (p. 98). When readers can enter this space, they are able to develop empathy for those in particular situations. For example, when looking at the education system, outsiders can better understand the lives of students, teachers, and even administrators by viewing them through a more emotional, metaphorical lens. This could essentially lessen alienation and create a bridge between those working in the schools and those who do not. 
Marshall and D'Adamo (2011) describe one form of arts-based research called the art practice-as-research approach. This approach involves analysis, description, reflection, and connection. According to Marshall and D'Adamo, this approach has also been shown to make learning deeper and more creative and has even changed students' views of themselves as artists as well as their views of art in general. This form of documentation is also similar to visual process diaries (Board of Studies NSW, 2003) that students use to explore a variety of art-making materials and processes, using text, images, reflections, and teacher feedback, to essentially discover the most successful way to complete an artwork. These diaries include images both created or pulled from other sources, class notes and/or handouts, descriptions and analysis of others' artwork, descriptions of their own thought processes, and any further research to help support their concepts.

\section{Importance of Visual Process Diaries}

Delacruz and Bales (2010) explored the importance of recording stories through portfolios, scrapbooks, and sketchbooks. They compare the work of preservice art teachers' digital teaching portfolios, scrapbooks from people in the community, and the sketchbooks and journals from artists. They discovered many ways journals and sketchbooks benefitted artists by keeping them grounded when they are overwhelmed by a large upcoming project, through the organization of experiences and recorded self-reflection. When discussing the purpose of students keeping a portfolio, journal, or sketchbook, Delacruz and Bales explained that these things "may each serve as a means of making special 
and strengthen student identities that are in the process of developing" (p. 39). This type of process, using both visual and written text in reflection, is especially important for students in a secondary classroom as they are constantly trying to figure out who they are and who they wish to become.

Process diaries can even be implemented into subjects beyond the art room. Leigh (2012) explored the ways sketchbooks could enhance writing in high school English classes. She described sketchbooks as the "doorways to [students] private worlds" (p.539) and explained how they are filled with various potential from visual thinking to "idea launchers." Leigh also argued that by combining artistic practice and language, students can discover language in a new light. While her focus was to benefit an English classroom, this concept is also significant for an arts classroom considering many artists like Joseph Kosuth, Glenn Ligon, and Jenny Holzer use language within their work.

In New South Wales (NSW), Australia process diaries are a required part of art education where some students spend years developing ideas for projects through their diaries (Holmes, 2002). Helen, an art student in NSW, worked on her ideas for two years in order to create one painting. Her diary began with the word "autonomy" and its definition as well as her personal reflection on the word. Helen included photographs, magazine images, sketches, symbols, and experimentation of various media techniques. Wenger (2002) observed this process and strongly believes process diaries would benefit American classrooms. Wenger argues that the development that takes place through these journals helps the student and the teacher. The student stays engaged with the 
class, and the teacher is offered a better understanding of what the student wants to do and what they have learned throughout the course.

The NSW Years 7-10 Syllabus also describes the diaries as being a connection between the teacher and the student (Board of Studies NSW, 2003). It is meant to record the student's original concept while leaving opportunity to resolve problems and make changes or try alternate interpretations for the final work. The diary becomes a way for the student and teacher to communicate ideas about different views, experimentation, and other art making processes. It is also important to examine the diary in relation to the final artwork, to determine the students' thought processes. Process diaries, however, never serve as a replacement for the final work.

\section{Integrating Diverse and Contemporary Artists}

According to Morgan (2012) misrepresentation and underrepresentation are common themes in materials used in American classrooms. It is important for teachers to be aware and critical of the way children's books portray people and cultures because children's books often downplay equality of gender and display an unauthentic identity of ethnic and racial minorities (Morgan, 2012). Morgan argues that Native Americans in children's books for example, are often represented as uneducated and uncivilized, dressed in feathers and animal skins, while their culture is ignored. She states that Native American authors, who provide a real perspective of their culture, are often ignored in schools, while stereotypes continue to be perpetuated. 
The history of African American literature shows it was often omitted from schools and children spent time reading only from the perspective of white culture (Morgan, 2012). Morgan states that today, schools have improved integration of African American perspectives and more authenticity of AfricanAmerican culture, but they still have a long way to go. African Americans are now seen in a more positive light in literature than in the past, however, intimate relationships between African Americans and whites are lacking in books. Morgan (2012) also explains that researchers have discovered many stereotypes of other cultures in recent publications. For example, many representations of Africa show only poor, malnourished, and primitive cultures.

Morgan (2007) and Rosenberg and Thurber (2007) found that misrepresentations of gender are also a concern in school materials, as males are seen much more than females. Their research has even indicated that the portrayal of women verses men is negative as well, and that female roles are often seen as submissive and dependent. Morgan as well as Rosenberg and Thurber argued that while there has been a shift in representation from history, not much has changed in the realm of sexism in books.

In order to avoid these negative representations of people, teachers should steer away from these types of books that perpetuate these types of stereotypes as much as possible. Rosenberg and Thurber (2007) argued that teachers should also focus on integrating various backgrounds and cultures into their curriculum in order to help diverse students feel welcomed and appreciated. This type of curriculum benefits all cultures because it teaches students to be 
more open to cultures outside of their own, which is especially important with growth in diversity and globalization.

\section{Need for Reflection}

Many teachers are becoming more interested in multicultural teaching due to the diverse population of their students and the necessity of understanding and teaching various cultures. Hidalgo (2012) has argued that before teachers can truly integrate multiculturalist methods, they need to reflect on their own culture and perspectives and question the ways their cultural perspective plays an overall view of the rest of the world. This way, teachers can determine what type of framework is being brought into the classroom. By engaging in this reflection, teachers will have a better understanding and respect for the different perspectives of their students.

Self-reflection is also necessary for improvement. Danielson (2009) has pointed out that teachers often face difficult situations that can become worse if ignored. She argues that teachers need to reflect on the tough choices they make each day in order to decide whether or not they are handling things in the best possible way. She also believes that reflecting helps teachers develop a better understanding of why certain methods work and why other methods don't. When teachers know why they are successful they can repeat these choices and avoid the ones that don't work.

There are many different ways a person can approach reflection. Cox (2016) argues the first step is to decide what needs to be evaluated. A teacher may be interested in figuring out whether the chosen teaching methods are 
successful or whether a specific problem is being handled correctly. Once decided, the next step is to gather information to be analyzed. Cox believes you can do this by creating a journal or keeping notes after every lesson that is taught. She believes another way to gather information is by video recording lessons. This can be very beneficial because it provides unbiased documentation of what is happening in the classroom. Student observations can also be helpful because they offer an explanation of what it's like from the students' perspective, which is very important when determining what they did or did not understand from the lesson and why. This observation can take place through student written or oral feedback and by grading student work to look for understanding and growth. Finally, Cox states that receiving feedback from a colleague other than a supervisor allows for an alternate perspective from someone in the field without putting extra pressure on the teacher.

Self-Reflection has been beneficial in other fields, so why not use it to benefit teachers? Edwards (2014) describes the importance of her personal stories during her clinical experiences for a nursing program. She believes that being able to read her stories again and again made it possible to cope with emotions and understand different situations. She also argues that this story telling can explain things like "problem solving, reflection-in-action, and unpredictability of the environment in which [nurses] work" (p.2). I think most teachers would agree that while the two careers are different in many ways, educators also experience problem solving, reflection-in-action, and an unpredictable environment. 


\section{Positive Reinforcement}

Whether you are a parent or a teacher there are different ways to deal with disciplining children. Ahmann (2014) describes a parenting technique developed by Glasser called the "Nurtured Heart Approach," which embraces positivity and rejects negativity (Glasser \& Easley, 1999). While some parents take a more traditional approach by disciplining their children for bad behaviors, Ahmann argues that this can cause problems for certain children as it brings attention to the unwanted behaviors, rather than focusing on the preferred ones. Ahmann references techniques like "Love and Logic" and "Total Transformation," but feels Glasser has had the most success in not only making a difference in a child's behavior but also making a positive impact on self-esteem.

At its most basic form, the "Nurtured Heart Approach" restricts attention given for inappropriate behaviors and welcomes more responses to good behaviors, however it is more than just saying "good job" or giving other sorts of praises. Glasser's model asks parents to first recognize something the child did without evaluation, which shows the child that they are recognized but not being judged. 


\section{CHAPTER III}

\section{METHODOLOGY}

\section{Action Research and Autoethnography}

The methodology used for this study of my experience during my eightweek student teaching placement at a junior high school, included both action research and autoethnography. Klein (2014) described action research as a fieldbased study used to inform necessary change in methods. When using action research, teachers incorporate two methods, one called "reflection-in-action," which creates opportunity for teachers to develop their own theories of best practice, and another called "reflection-on-action," which analyzes what has happened in order to develop new plans of action. Klein explains action research as "cyclical in nature" because the process of reflection inspires a constant flow of problem solving and new questions about teaching methods.

Using this type of research in my study provided me with an alternative perspective of my teaching methods and abilities as a teacher. It also helped me analyze daily activities in order to make adjustments for future lessons. In order to complete this research I kept records of the unit, along with supporting materials that I developed specifically for the eighth grade class .I recorded daily reflections about my experiences and took pictures of student work as well. 
Incorporating autoethnography into my research, allowed me, the researcher, to "give voice to [my story], creating meaning through heuristic reflexivity, resulting in emergent accounts of that which is examined" (Anderson, 2014,p. 88). In order to integrate my personal perspective or "voice" I recorded daily journals and reflections of my experiences and included photographs of the environment and student work. Each journal was written either throughout every day of student teaching or immediately afterward in order to record my experiences as accurately as possible. The journal became a self-told story of my teaching, which was compared to the feedback from my supervisor and cooperating teacher as well as to student outcomes in order to check for veracity. Finally, I reflected upon the following methods within my teaching practice:

- Student Centered Teaching: Projects were flexible enough to allow students to integrate personal interests

- Process Diaries: Prior to making masks, students created visual process diaries to begin creating literal visualizations of idioms and reflect on the relationship between personal memories and the idiom they chose.

- Allowing room for mistakes: It was originally intended for students to have the opportunity to resubmit and reflect on the decisions they made in order for me to have a better understanding of those choices. Unfortunately, due to lack of time, I was unable to allow resubmissions and reflections. Grades that I gave were based on process and effort over final product.

- Integration of diverse and contemporary art: The lesson was intended to incorporate various artists and contemporary artwork in order for the lesson to be 
more relatable to students. I unfortunately was not able to incorporate various artists due to lack of time.

- Positive Reinforcement: I focused on positive behaviors by acknowledging and rewarding students for appropriate behaviors rather than bringing attention to unwanted behaviors.

Considering that this type of research is self-reflective, the university's Institutional Review Board declared that my research would not use what they considered to be "human subjects," and stated that I did not need their permission to conduct the study. I did, however, receive permission from my cooperating teacher to conduct my research. I also acquired signed assent forms from multiple students and permission forms from their parents to use the students' artwork and writing in my research. No names were used in order to protect the privacy of the students, cooperating teacher, and the school.

\section{Data Collection and Analysis}

Due to the type of research conducted, I am the prime source for collected data. This includes the unit plan that I developed specifically for the eighth grade class that I taught and feedback provided by my cooperating teacher. The majority of my data was retrieved from written reflections that I recorded throughout my eight-week placement, along with post-student teaching memory reflections. These reflections consisted of my personal perspective on my success and failures as well as the feedback provided by my cooperating teacher and university supervisor. 
Throughout my placement I was required to send any lesson plans and supporting materials to my cooperating teacher who would then provide feedback. My university supervisor also observed me twice during my placement; once in my first week of teaching (the third week of my placement) and again on my last week. This allowed him to discern whether or not I showed growth throughout my teaching experience. The final portions of my data were images of student work.

\section{Participants}

The study included my cooperating teacher, feedback from my student teaching supervisor, and students from one eighth-grade art class at a junior high school. My cooperating teacher received her Bachelors in Art Education from a university in Central Illinois and began, but did not complete a Masters degree from the same university. She has approximately fifteen years of teaching experience during which she has worked only at the junior high level and at the same school. My university supervisor received his BFA in painting and printmaking from the Kansas City Art institute, an MS in art education from Truman State University, and a PhD in curriculum and instruction with a focus on art education from the University of Missouri-Columbia. He also has thirteen years of teaching experience at the high school level and seventeen years of experience teaching at the university level.

The study took place at a junior high school located in a town in Central Illinois with an enrollment of 895 students. The junior high school is made up of $30.8 \%$ low-income students, $1.1 \%$ homeless students, $1.7 \%$ ELL, and $12.4 \%$ of 
students with disabilities. The school is considered to be racially diverse with the student body being made up of $69.7 \%$ White, $12.4 \%$ African American, $4.6 \%$ Hispanic, $6 \%$ Asian, . $3 \%$ American Indian, and $6.9 \%$ two or more races. The class size averages 27.5 students (Illinois Report Card, 2015).

According to the 2014 census, the town's population was about 54,594 with $85.1 \%$ White, $8.1 \%$ African American, 4.1\% Hispanic or Latino, .2\% Native American or Pacific Islander, and 3.2\% Asian (US Census, 2014). The median income for households in 2014 was $\$ 52,134$ and $24.5 \%$ of the population was below the poverty line.

\section{Limitations}

Limitations included student absences and lack of input from the cooperating teacher including a very small amount of verbal feedback. There were also limitations on what methods could be introduced to the class and how students responded due to unfamiliarity with those practices. Since the study took place during an eight-week student teaching placement, there were limitations on the amount of time I had to teach my unit. The original amount of time planned for this particular unit was shortened due to the need for extensions of the previous assignment. Limitations also affected what lessons could and could not be taught because the use of various media was pre-arranged and content that reflected social issues was deemed inappropriate for this age group.

\section{Summary}

This study was developed mostly from personal reflections of my teaching experiences during my eight-week student teaching placement at a junior high 
school in Central Illinois. It followed a personally developed unit plan, specific teaching methods, and reflections by me as well as oral and written feedback from my supervisors and oral feedback from students. I compared the differences and similarities between what I had planned on happening with what actually happened to track what unpredictable changes were made throughout my teaching experience. This offered insight into what teaching methods worked best for me as well as for my students.

Some of the ways I attempted to approach teaching during my time at the middle school included self-reflection, student-centered teaching, flexible grading that leaves room for mistakes and resubmissions, process diaries, and the integration of diverse and contemporary artists. I believed, as Cubukcu (2012) observed, that student-centered teaching would provide opportunity for students to be more in control of their learning process by making information relevant to their lives. I also wished to create an environment that pushed for a "growth mindset" where students put in effort because they were not afraid to fail and understood that mistakes are a part of the learning process. According to Dweck (2007) this process should emphasize the need for exploration and make students think more critically.

The integration of process diaries was intended to support the need for exploration; the diaries could give students the chance to experiment and reflect on their ideas (Board of Studies NSW, 2003). The diaries were to incorporate both found and created images, drawings, paintings, mixed media, and written notes that included personal reflection and exploration of other artists. Finally, I 
included more diverse and contemporary artists in the unit plan to be considerate of all student identities and continue to make the information relevant to each student. By incorporating diverse artists I intended to teach students about cultures and identities with which they were unfamiliar and to encourage students be empathetic towards different perspectives (Rosenberg \& Thurber, 2007).

At the end of my study, I composed a final conclusion of my overall experience. Dewey (1916) argued that people couldn't fully understand the meaning of their experiences if they did not examine the links between actions and consequences. Through self-reflection I hoped to have a better understanding of the teacher I am as well as the teacher I wish to become. The study attempted to push me to examine my strengths and weaknesses and reflect on how to be better for my students. This process will, hopefully benefit my future students, as I will comprehend more conclusively practices that will encourage and motivate students to be successful in my classroom and in other areas of their lives. 


\section{CHAPTER IV}

\section{ANALYSIS}

\section{Analysis Background}

The purpose of this study was to reflect upon my abilities as a teacher. This reflection included the student reception of the unit that I created and the teaching methods that I used. In order to guide my research, I developed the following questions: In what ways did I develop as a classroom art teacher during an eight-week student teaching placement at a junior high school? What teaching methods were successful or unsuccessful? What changes could I make in my future classroom to help me and my students become more successful?

\section{The Frames}

When addressing the first question, I felt it was necessary to explain my process of planning the unit. While learning to be an educator I was introduced to various methods and theories that could be used in my future classroom. These include everything from planning a lesson and discipline techniques to the actual art of teaching. As I started to plan my unit for this study, I spent little time focusing on why I made certain decisions or why I purposefully incorporated previous teaching techniques that I had learned. After reviewing the unit plan however, I used metacognitive practices to help reveal what methods impacted me most during my educator training. Ambrose, Bridges, DiPietro, Lovett, and 
Norman (2010) explained that using metacognitive practices, or reflecting on ones own thinking, is very effective when training yourself to become a selfdirected or life long learner and is especially important at higher levels of education.

While thinking back to my process in unit development, the first part of my training that came to mind was the use of the New South Wales (NSW) curriculum model. In order to organize content used in NSW art classrooms, teachers use three different areas that connect to art making as well as critical and historical perspectives (NSW Syllabus, 2003). The first area is Practice, which is comprised of the art that students create as well as student's critical and historical interpretations of artists' practice and collaborations, negotiations, and relationships that compose it. The second area is the Conceptual Framework. This framework is used to identify the connections between the artist, the artwork, audience, and the world and it reflects the relationships of the art world. The Frames are the last of the three areas used to organize content and the most influential to me when creating my unit. The Frames provide teachers and students different theoretical lenses to look through when observing artwork in order to engage in different values, beliefs, and perspectives within the art world.

While Practice and the Conceptual Framework are very important within the NSW curriculum, I found the Frames to be the easiest to integrate into an American system. Rather than having to introduce an entirely new curriculum I could use the Frames as a guide when developing my unit plan as well as creating questions that went beyond formal qualities of an artwork. By 
incorporating the Frames, I was able to push my class beyond the stereotypical art room where students just glue things together, and instead taught students art as I believe it was meant to be an intellectual process. In order to fully understand this process, it is important for me to describe the different Frames and how they could be used in an art classroom.

The first Frame, and the one I find to be the easiest to incorporate into my planning, is the Subjective Frame. This Frame explores feelings, emotions, imagination, and psychological experiences when looking at and creating artworks (NSW, 2003). When developing my lessons, I use this lens as a guide to ask questions that focus on emotions and how the artwork makes the viewer feel. For example, the first time I saw Picasso's Old Guitarist, my initial feeling was loneliness. The deep shades of blue that covered the canvas and the exaggerated figure felt cold. This made me question who the figure was and why an artist like Picasso, known to me at the time for his colorful Cubist work, would paint something of this nature. It is this question that can lead an observer further into the work to focus on the Cultural Frame.

The NSW curriculum describes the Cultural Frame as a way of looking at social, economic, and other cultural constructs within an artwork. Artists are often influenced by their surrounding cultures and this framework provides the audience, in this case the students, with a guide to ask questions about the issues and ideas important to them (NSW Board of Studies, 2003). When looking back at Picasso's Old Guitarist for instance, one might ask "What was happening 
in the world at the time of this painting?" or "How was the artist affected by social issues and ideas?"

The third Frame used in the NSW curriculum is the Structural Frame. This Frame is most relatable to a standard American art curriculum that emphasizes elements and principals of art; it refers to the formal qualities of an artwork as well as its symbol structure. When making artwork students learn how to communicate ideas through color, composition, and spatial relationships. Again, using Picasso's painting as an example, a discussion might evolve around the idea of color and the elongated figure, which can be interpreted as cold and bizarre or unnatural.

The fourth and final Frame focuses on a postmodern viewpoint, which "brings challenge/doubt/suspicion/skepticism to the assumptions of each of the other frames" (NSW, 2003, p.24). The Postmodern Frame sees the image or artwork as a text, which develops meaning through its relationship to other works, or texts. For this reason, the Postmodern Frame invites the viewer to compare how a work is currently perceived to the time that it was originally made and analyze the power structures that might have surrounded it. This Frame also focuses on appropriation and modification of alternate images in order to create new meaning.

Since I learned about art in a typical elements and principles curriculum during my own time in public school, artwork tends to be easier to observe through a Structural Frame, rather than through a Postmodern Frame. However, these lenses have helped me think beyond the material and develop a better 
understanding of content and the relationship an artwork has to the rest of the world. The Frames provide the viewer with opportunity to investigate meaning and ideas in art that may not have been seen before (NSW, 2003). The Frames also provide ways to develop a curriculum, questions to ask, and a language for art through metacognitive means (Freeman \& Sanger, 1993).

Another important factor in using this model is the research that goes into developing a unit plan. Rather than picking an artist and asking students to make a copy, I found it was important to discover as much as I could about the artist, his or her work, and his or her practice in order to create better opportunity for students to fully engage with the work. When my research was complete, ideas and projects started to reveal themselves. This process made it much easier to develop a lesson because I had an in-depth understanding of what the artist was thinking when the work was created and how it fit into the larger world.

Considering that this type of model is used in a different educational system than the United States, I always wondered how I would be able to incorporate it into my future classroom. It didn't seem realistic to try and teach students the different Frames and specifically reference them during discussions and critiques, however there was still a way that they could be beneficial. Rather than focusing on key terms like "Structural Frame" I could use questions to focus students on structural issues when looking at work and generating questions for my students. This process also provided me with a tool to organize and clarify the requirement of integrating National Visual Arts Standards into my lesson plans. 
The National Visual Arts Standards are important to each lesson because they reflect what students should be able to do and know at different points throughout their education (Learning Standards, 2014). Standards are typically broken into subjects and grade levels to create goals for what students should be able to achieve prior to moving forward. While certain abilities are highlighted in the standards, freedom exists in curriculum development for individual districts, schools, and teachers. For example, the Visual Arts Standards are broken into sections of creating, presenting, responding, and connecting. While one standard might be geared toward a student being able to convey meaning through an artwork, there are no specifics on how the student should approach this task, which gives room for variety within lessons from classroom to classroom.

Conveniently, the standards parallel nicely with the Conceptual Framework, which also guides students in their process of creating, presenting, responding, and connecting. When asking questions using the frames, students are able to think about the structure of an artwork and apply what they learn to their own creations. Students also must think about how they are presenting their work when looking at art through the artist, the artwork, and the world. Including questions that will pique student interest rather than providing information for students to memorize. This process of asking questions helps with student development of knowledge because students then become more engaged with the information (Bain, 2004). 


\section{Curriculum Creation}

Through the course of my education I came up with an excellent system of creating lesson plans and unit plans and in this chapter I will mostly focus on one developed for the eighth grade class during my placement. While this system may not work for everyone, it turned out to be very helpful during my student teaching placement. According to Bain (2004) some teachers pay too much attention to what they do rather than putting the focus on what students are supposed to learn. He found that the best teachers would ask themselves how they could assist and encourage students to learn and create an environment that supports student engagement. In order to practice best teaching methods, the first thing I consider when writing my unit is the art form and the methods students need to learn. Is this lesson going to be a two-dimensional or threedimensional project? Do the students need to learn about color theory, painting and drawing techniques, or develop fine motor skills?

Once I have an idea of the art form, materials, and student goals I want to incorporate into the lesson, it makes it easier for me to find an artist whose forms and concepts align with those that I am using. I can narrow down what type of artwork I am looking for and then reevaluate my materials after discovering more about the artist's content that draws my interest but more importantly, as Gardner (1987) advocates, connects to the students' interests in order to keep them more engaged in the lesson

Using the NSW curriculum and arts-based educational research as a guide, I then seek to discover as much information about the artist and her or his 
work as possible. This allows me to determine which ABER approach is best. For example, if the nature of the artwork explores social issues, which falls under the first approach according to Greenwood (2012), I may incorporate this topic further into the lesson. If however, the artwork is broader in its content I can use the second approach in which the artwork is the main focus and layers of content unfold throughout the lesson. This is also important to consider when teaching different age groups because some topics (such as specific social issues) may be more appropriate for older students.

After determining which approach I want to take, I use the Frames to guide my questioning and discover ways to make the content relevant to my students. Having knowledge about your students becomes extremely helpful in this part of the process because it pushes one to make decisions based on what students would like, rather than just incorporating one's favorite artists and projects. Garion (2002) argues for student-centered teaching and this is one strategy to put student interests at the center of the curriculum rather than the teachers. According to Pajares (2003) creating plans based on student interests can also add variety to your class each year because you can tweak and change the lessons accordingly.

Once I have decided on an artist, I can search for supporting artists. This provides the students with different perspectives on an idea and can open a more diverse artist pool. If a student does not identify with the first artist, they may have a better connection to or understanding of a supporting artist. Picasso, for example, is an artist many students are familiar with due to his fame; 
however, his work may not be the most interesting, because he is not referencing today's world. To push students toward making connections, one could integrate contemporary artists into the mix in order to put the focus of the curriculum back on the students as Garion (2012) suggests.

After gathering the necessary research, I usually develop a project plan and begin to write my lesson or unit. This is often the most difficult part because I always try to make sure my lessons build on each other. Jensen (2005) explains that prior knowledge should be used in order to link new information to what students already know. By using this scaffolding method where lessons build on each other, students can slowly connect one concept to the next rather than being overwhelmed with too much information (Bain, 2004). Once I feel my unit transitions smoothly, I can start to finalize details such as learning objectives and assessments.

The learning objectives are a key component to any lesson or unit because they are goals for what students are expected to accomplish throughout a lesson, unit, course, or even the year (Learning Objectives, 2014). These objectives help teachers organize and structure their lessons to appropriately fit the age group and prepare students for their next step. The objectives are also important because they are used as a way to assess student learning by deciding how well, if at all, an objective was met.

\section{Developing My Unit}

The summer prior to student teaching I spent hours researching a diverse range of artists and brainstorming potential projects. At the time I had not been 
given direction by my cooperating teacher as to what art form or materials I would be teaching, so I did my best to look at different media. After speaking with my cooperating teacher, however, I realized I would have to start fresh. Due to my strong ceramics background, she wanted me to develop a lesson using clay for the eighth graders, and that happened to be the one area I did not research as I felt I already had sufficient ceramics lessons for reference.

Prior to the development, I decided to search through old lessons to see what I could tweak to fit with this group of students. Since, at this point I had learned very little about the students, and student-centered learning was very important to me, I wanted to find a project that I had previous success with and that was flexible enough to allow students to contribute their interests. While I try to make all my lessons relatively flexible, I became inspired to create a brand new lesson for this group because it gave me extra practice creating a lesson and the opportunity to include all of my preferred teaching methods. I continued to find myself thinking about a mask unit because not only do the majority of students love the idea of making masks, they could also become very personal.

Now that I had a base for my research, I followed the steps in my system and began to look for artists. Although I had used mask makers in the past, I felt it was important for me to find someone new and broaden my personal knowledge of artists. I eventually landed on ceramicist and mask maker, Peggy Bjerkan. Her masks typically start with an elongated human face and slightly disproportioned facial features. With added sculpted details and colorful glazes that reference animals, vegetation, body parts, and more, each mask represents 
a hybrid face that references an idiom or common phrase. My initial reaction to her work was that the masks were intriguing and most likely different from what the students had seen in the past. I also appreciated that I would be able to incorporate a female artist to create some diversity, considering the previous artist students studied was male. I found this to be very important because according to Morgan (2012) there is not only a misrepresentation of women in contemporary classrooms but also a lack of females all together.

The mask making project idea was intriguing because I thought it could be an opportunity to show masks in a different light than one often stereotyped. When I think back to masks I learned about as a student, the first lessons that appear in my mind are African Masks. The problem is not only did I spend time believing that all Africans were part of tribes that used masks, I also had no understanding that various cultures use masks in different ways. Gay (1992) argues many teachers look to catalogs of learning activities and resources that integrate various ethnic and cultural groups. However, the materials they use are often too general, show the perspective of the maker rather than the culture, and are outdated. I decided Bjerkan's work would be a good starting point because the masks would be different than what students were used to seeing, yet I would still be able to integrate a discussion on different types of masks while doing my best to avoid stereotypes.

In order to learn more about Bjerkan's perspective and artwork, I began to read articles and personal blogs. After discovering that Bjerkan's masks are often influenced by idioms that relate to personal stories I was immediately inspired 
and decided her work would be a great starting point for students to make direct connections to their lives just as she did with her creations. Rather than trying to appropriate and misrepresent another culture, students would be able to make an original mask based on similar ideas to Bjerkan. They could choose an idiom that related to personal story and use it as a beginning point for their masks. The integration of an idiom would also be interesting to use because students in this age group are often intrigued by wordplay (Hurwitz, A. \& Day, M., 2007).

While at this point I would normally begin searching for supporting artists, I decided to take a different approach. In a blog, Bjerkan (2011) had explained that she creates masks because they have been important throughout history in various cultures and can tell different stories. This opened a door for me to incorporate a multicultural approach to the lesson and explain different purposes and meanings for masks. Instead of spending time researching other artists, I focused my research on other cultures in hopes to represent them in a more appropriate way.

Within the unit I decided to focus on classic Greek theater masks, Chinese theatre masks, and Dogon masks. When teaching about the Greek masks I felt it would be good to discuss the use of exaggerated expressions, which were used to help the audience members in a large theater see the features of the characters (Pike, 2016). I would then incorporate Chinese theatre masks into the discussion in order to compare the two types of theatrical masks. One important element of these masks is the use of color symbolism (Chinese Masks, 2014). Discussing the use of color to symbolize various ideas could open the 
opportunity for students to think about use of color in their visual process diaries and on their final masks. Finally, I incorporated the masks of Dogon people, specifically those called Kanaga. The Kanaga masks are worn during spiritual rituals performed with the purpose to transport deceased souls away from the village (Mask (Kanaga), 2016). Rather than using another example of a mask used for disguise and entertainment, I wanted to introduce students to a purpose they may not already be familiar with and use the opportunity to discuss overgeneralization of cultures.

Once I had materials and artists I started to write my unit plan. Since Bjerkan uses idioms as inspiration I decided this was a good starting point. My plan for the first day was to incorporate active learning by writing an idiom on the board and having students draw a literal representation of the idiom. Using active learning was another way for me to integrate a student-centered teaching approach and hopefully immediately engage students (Felder, n.d.). From there, we would discuss the definition of "idiom" and students would work in groups to write down those idioms they knew and those they found. Since the students would eventually make their own versions of a mask based on Bjerkan ideas, it was important to find a method for the students to begin to visualize these idioms. To achieve this, I decided to incorporate a game of "Pictionary" where students would take turns pulling a slip of paper with an idiom written on it and then to their best to draw the idiom on the board. This would not only allow the students to begin visualizing idioms but it would also give them an opportunity to apply their skills. Ambrose et al. (2010) explains the importance of allowing 
students to apply skills across multiple contexts because students will then become better at transferring their skills and apply them elsewhere.

The next day I would introduce brainstorming packets (Appendix C). These packets would be used as a way to break down and organize information in order to avoid overloading and overwhelming the student's minds (Jensen, 2005). In the packets there was a list of idioms and their meanings along with worksheets that asked questions to guide their thinking. These questions or prompts would also assist in student transfer. Ambrose et al. (2010) explains that students often have the knowledge or skills to solve problems but are not aware. By incorporating prompts, students can make connections between old knowledge and new tasks.

Within these prompts, students would be instructed to choose an idiom that represented a personal memory. For example if they picked "Change of Heart" they could describe an important time they changed their mind about something. They would then record their idiom, their personal memory, and create a literal drawing of the idiom they chose. They would also reflect on the importance of their memory and why it related to that idiom. While I felt a packet was necessary to support their project development, I wanted to make sure the students could still incorporate their own interests in order to promote free thinking and creativity (Hurwitz \& Day, 2007).

The next step would be for students to use their packets (Appendix C) as a guide for their visual process diaries. This would help the students break down the information and focus on small bits at a time rather than overwhelming them 
with too much information. According to Jensen (2005), the brain needs time to organize when integrating and storing new information. This means teachers need to present less information over small amounts of time so students have the opportunity to retain new information and make connections to what they already know. By breaking down the packet and allowing students to focus on sections at a time, I would be providing them with a chance to learn and reflect rather than memorizing and forgetting.

In order to show what is expected within the packet, I would show them my teacher example and explain what ideas needed to go on each page. For example, the first page would contain the idiom, the definition of the idiom, and a visual representation. I would push students to be creative by giving them the opportunity to pick the way they wanted to format the required information and allowing them to use any materials that they wanted. This would be another way of integrating a student-centered approach because it would give students many opportunities to choose (Cubukcu, 2012). The main purpose of the process diary would be for students to make deeper connections between their personal memories and the idioms while developing sketches for their final mask project; the masks. The process diaries would also help me understand the thought process behind each mask, which would be important when grading and discovering what the student learned during the lesson (Wenger, 2002).

Finally, the students would be introduced to information about clay and different techniques they could use when creating their masks. My plan was to introduce the basics of working with clay such as the different stages (e.g., 
plastic, leather hard, bone dry, bisque ware, and glaze ware), slip and score techniques, and the importance of removing air bubbles. I also decided it would be beneficial for students to use balled up newspaper as a slump mold for their masks because newspaper is easy to find, the masks would become more three dimensional, and I could integrate information about using a mold.

After teaching students the need-to-know information about working with clay, they would move into the clay room where I would be able to discuss rules and do small demonstrations such as rolling out slabs, creating the molds, attaching pieces of clay to the body of the mask, and carving into the clay surface. Integrating a demonstration on how to use materials is one way to incorporate differentiated instruction, which is a great way to reach all learners (The three principles, 2014). By showing students the visual step-by-step process rather than just relying on the information provided earlier through instruction and packets, visual learners would be able to grasp the concept further. After giving the demonstration, I would give students a chance to ask questions and then provide them with their materials to begin working.

When students complete their masks, the next step would be for them to write about what they made. Similar to reflections in the visual process diaries, this written work would provide me with a better understanding of their perspective while at the same time gauging what they learned throughout the process (Wenger, 2002). I would ask them to reflect on why they chose their idiom, how their ideas for their mask changed after they starting making it, what they learned from the assignment and what they did and didn't like about the 
project. Getting feedback on the lesson from the students would also be a great way to receive another perspective on how I can make the lesson better for next time (Cox, 2016).

For the final portion of the unit, students would take part in a critique. Having the students write first would give them time to develop their ideas in order to be more comfortable talking to the rest of class. After the pieces were fired, I wanted to have the students set up their masks in the room and take turns discussing their pieces while referring to the writing. I would then allow the rest of the class to ask questions, make positive comments, or give constructive criticism. This would be one way to provide feedback to each student. Ambrose et al. (2010) explains how effective feedback is essential for students or learners to achieve their goals because it acts as a guide. Effective feedback tells students what they understand, what they don't understand, their level of performance and how to make adjustments in order to improve.

\section{Teaching}

Creating a unit is a fantastic way for a teacher to organize what they want to happen each day (Farrell, 2002). However it is also important to remain flexible in order to adjust for unforeseen problems that arise when teaching. My discussion of the changes that occurred from unit development to teaching will include my teaching experiences based on personal memories, reflections in my journal, and reflections given to my university supervisor throughout my placement. 
My first two days of observation consisted of students completing a watercolor grid of various techniques taught to them prior to my arrival. When the students finished their grid, they practiced a few techniques of their choice by drawing and painting a zentangle. These cooperating teacher created activities were meant as practice for the final assignment, which was to find a picture of a landscape and paint it using different watercolor techniques. When finished with the painting, students were instructed to write a quote of their choice in the background using sharpie.

My first day of taking over the classroom took place half way through the watercolor unit when students began their final paintings. This was difficult because I was not present when the lesson was introduced, and I was not attached to the lesson theoretically, intellectually, or emotionally as it was not my own. I started slowly by providing directions in the beginning of the class, assisting students as needed and dismissing tables to leave at the end of the period. I was thrilled to finally be able to completely take over when I began teaching my unit.

The eighth graders were accustomed to coming into class with some form of a bell ringer or short activity for students to complete in the beginning of class to allow time for students to settle in and give time to the teacher to complete small tasks such as taking attendance. In the past, my cooperating teacher would assign the students something to draw in their sketchbooks like their favorite food or a place they want to travel. 
While this system gave my cooperating teacher a chance to take attendance, many students seemed to be uninterested in completing the bellringer even though it would be graded. I decided it would be good to at least start my unit incorporating some form of a bell-ringer to keep the students in a familiar routine because as Jensen (2005) explains, keeping a routine can help maintain comfort and security. At the same time however, I felt it was important to change the bell ringer enough to grab the attention of the entire class.

\section{Day 1}

My plan for the first day was to have an idiom written on the board and ask students to create a visual interpretation as their bell-ringer. Being the first class of the day, the students would enter the room sporadically and my cooperating teacher would often repeat herself by telling each child what the assignment was as they entered. For this reason, I decided to write the bell-ringer assignment on the board and waited for the majority of the class to arrive. I then passed out separate pieces of paper rather than referring them to their sketchbooks to make it seem like we were doing something completely different. Although these were small changes, it appeared to work because the students were attentive and ready to see what was coming next.

As students filed into the room they noticed the large words written across the board that read "When Pigs Fly." I chose this idiom because it is well known and was simple enough that the students could create a drawing that was reflective of the words. Once the students were settled, I handed out the paper and gave instructions to create a drawing that reflected the phrase on the board. 
The students began to draw, and I was surprised to see the variations they created. A few students created less complex works, but others put a great deal of time into their drawings. One student even incorporated red-bull because the word "fly" made him think of the slogan "red bull gives you wings." It was interesting to see this student begin to make metaphorical connections as those created with the use of language in ABER methods (Barone and Eisner, 2012) because he started to become active in the process in a way that was beyond what I had initially expected.

It was also pleasing to see that each student put effort into his or her bellringer drawings because during my observation, half of the class would ignore the bell ringer exercises and settle into their seats while talking to their peers or even staring out into nothingness. This made me feel that they enjoyed the assignment, but it also could have been out of respect for a new teacher.

When the students completed their drawings, I asked for volunteers to show their creations so they could see what their peers had made. I then decided to test out their previous knowledge by asking if any of them knew the meaning of "When Pigs Fly" or if they could tell me the type of phrase. This process was different than previous assignments because this time students were prompted with questions and asked to make interpretations. By discovering what student already knew about the topic, I was able to make decisions on how I could build on their prior knowledge as Jensen (2005) suggests. According to Danielson (2013), this pre and posttest technique could also be used as an assessment, 
which would help me analyze what students learned during the lesson about idioms.

After asking the second question, I noticed I had more participating hands for the first one when one student made an attempt to describe the meaning of an idiom. It turned out that none of them knew what an idiom was, so it was exciting to learn that I would be able to teach them a new vocabulary term. In the next part of the lesson students worked in groups in order to brainstorm other idioms they knew. I distributed to each group thin slips of paper for the groups to write down each idiom they remembered. By allowing group work I was able to switch the mode of instruction and create a different type of work environment in order to include differentiated instruction and give students an alternate mode of expression and understanding (The Three Principles, 2014). As I walked around the room I saw students talking about and writing down a wide variety of idioms. One group, however, really struggled, so I said that they could use their computers to spark more ideas. I wasn't sure if they were simply stuck or had little knowledge of idioms and decided it was important to give the group additional support in order to build on their prior knowledge and keep them on the right track. Bain (2004) explains how students try to comprehend new meaning based on material they already know and are familiar with which means students can interpret information differently than intended if they have no previous knowledge of a subject. By allowing them to do research on the computer, my hope was that they could create knowledge for the task at hand. 
After this group found a few examples they began to think of more, which led me to believe they had the prior knowledge of idioms but simply weren't aware until they were given more information. As students finished I asked for volunteers to raise their hands and tell the class one idiom that they had written down and what it meant. This took up more time than had I originally expected because the students were very creative, came up with a multitude of idioms, and had few repeats.

When students finished sharing with the rest of the class, I collected the slips of paper and put them into a jar. I then separated the class into two groups in order to play idiom Pictionary. When I asked the first team who wanted to draw, they were pretty shy and it took some time for someone to finally volunteer. This quickly changed and soon students were reaching higher and higher for me to call on them. The teams went back and forth drawing idioms on the board and guessing. Since some of the idioms such as, "Bite off more than you can chew" were a bit difficult to draw, I would give the students the opportunity to choose again. I was thrilled to see each student at least try to draw whatever idiom he or she pulled, even when they were very difficult. This showed me that they were willing to try and fail rather than give up before even making an attempt. While I didn't originally intend for this game to incorporate an element of allowing and encouraging mistakes, I realized this is exactly what happened. By encouraging students to at least try it gave me the opportunity to praise them for their effort and push them toward a growth mindset advocated by Dweck (2007). 
Overall the activity was fun and every student was engaged and willing to participate in one way or another due to the competitive nature of the game. Jensen (2005) explains that there are various ways to create an environment that engages students and competitive activities are one of them. Jensen also describes how engagement can take place just by changing the classroom environment. By allowing students to get out of their seats and move around, I was able shift the environment just enough to pique student interest.

\section{Day 2}

On the second day I introduced the artist that inspired the lesson because I wanted to connect what students had learned the previous day (idioms) to new information (masks inspired by idioms) in order for students to make connections and build meaning (Jensen, 2005). I also felt it was important to introduce the artist at this time because it would provide them examples of what to think about when creating their next project, the visual process diaries. These diaries would be used as a way to develop ideas for their mask projects by incorporating drawings and written reflections that responded to the idiom each student wanted to use and demonstrate how it would relate to their personal story.

I showed the students multiple images of Peggy Bjerkan's masks and asked various questions including "What does this make you think of?" and "What idiom might she be representing?" I also gave the students some background information on Bjerkan to create connections between the artist and her work. Considering the students were not accustomed to class discussions, few students volunteered to answer these questions. Those who participated 
however, made great observations. One student commented on the relationship between multiple masks and idioms while a few other students described two of the masks as being "creepy" and "unsettling".

As a class we only discussed the artwork for about fifteen minutes, which is shorter than I initially planned. Normally, I would hope to use at least one full class period to discuss artwork. Because the students were not used to this type of instruction, it apparently made it difficult for them to fully engage with the questions especially in front of their peers. I also had a limited amount of time to teach the unit, which forced me to condense the time I left for discussion.

After viewing and discussing the artwork, I introduced the assignment. I explained that the students would be making masks to which the responses I received were "Woo!" and "Really!?" I was thrilled that everyone was excited to create a mask. However, this was just one part of the assignment, and I hoped the excitement would continue to erupt from the room. I explained that each student would choose an idiom that reflected a personal memory. They would then create a visual process diary that included images and writings about connections between their memory and their idiom. Since they had never created anything like the process diary, I had no prior knowledge to scaffold from so I decided to make a step-by-step packet (Appendix C) to guide them in hopes of breaking up the information and enhancing learning (Jensen, 2005).

After I completed the packet I was optimistic about the potential for its success because the information was simple enough for the students to follow. The packet also incorporated specific instructions while at the same time created 
freedom for creative and personal touches. The packet included a list of idioms and their meanings along with a layout of what needed to be included on each of the three pages of their process diary. While certain things like the written idiom and a visual interpretation were required for the first page, the students were free to use the materials of their choice and arrange the information however they wanted. This was another way I was able to incorporate a student-centered approach because they had full freedom to be creative (Pilecki and Sousa, 2013)

While the visual process diaries were only being used as a stepping-stone for their final project, it would be worth points and was going to be graded. Originally I wanted the students to have a week to work on this assignment in order to spend time planning out what they wanted to do and to provide enough time to incorporate various materials. Unfortunately, the timeframe for the unit was shortened and the first unforeseen problem was headed my way.

\section{Day 3}

After reviewing the schedule with my cooperating teacher on Day two which was a Friday, she realized that I was not going to have sufficient time to complete my unit. The following week I would lose Wednesday because it was time for students to work on their career projects, and the week after I would essentially lose the entire week because it was shortened for Thanksgiving break. In addition the students were promised the opportunity to watch a movie as a reward for good behavior. Receiving this new information required me to rearrange my original plan. 
Day three was a Monday, and unfortunately, I didn't make it to school because I wasn't feeling well. I asked my cooperating teacher to give the students a workday because it was very essential they had time in class to complete as much as possible. While I was frustrated that I would not be available to help, I was happy that I had at least been able to introduce the assignment and give them instructions. Hopefully all they needed now was time to work.

\section{Day 4}

Even with the shortened schedule, I was able to give students another workday. I was thrilled to be back in the classroom and see the work my students had accomplished. The majority had made good progress with one or two mostly completed pages filled with drawings, writing, and color. Unfortunately they seemed hesitant to incorporate a variety of materials. None of the students took advantage of collaging images and only two students incorporated paint. The rest used colored pencils and gel-pens, which were materials that they had used in the past.

While talking with the students about their process diaries, I learned a lot about their personal lives. For example one student decided to use the idiom "pig out" based on a very traumatic event in her life. At a young age she was diagnosed with a rare disease, which kept her in the hospital for days. She was not able to eat full meals but she said when she finally had the opportunity to eat she was able to pig out. When telling her story she laughed at the memory and I was pleased to see she could use this project to relive that experience in a more 
positive way. These stories would have become extremely beneficial for further lessons if I had the opportunity to teach this group again because I would have more knowledge of student interests. Connecting new information to student interests creates a great impact on learning because students would find relevance in what they were learning (Pajares, 2003).

\section{Day 5}

Since the actual fifth day was interrupted by the career projects, I will continue by discussing the fifth working day of the unit. Knowing the visual process diaries were already interrupted, it was difficult to add more time to that break but it was my only option. After Thanksgiving break I would only have one week left to work with the students, which meant they would only have one week to complete their masks. Originally, like the sixth and seventh graders, the eighth grade students were going to be able to free draw or fill in coloring sheets provided by my cooperating teacher while watching the movie. In order to use my time in the best possible way, however, I decided to have the students work on their visual process diaries while watching the movie. This meant I would be able to end the week by talking about clay.

At the request of my cooperating teacher, I incorporated a slightly different version of her packets into the clay discussion. The packets copied the PowerPoint that I introduced and included areas for students to fill in the blank for certain clay terms and definitions. My cooperating teacher said this is how she has taught clay in the past and it made it easier for students to take notes while she taught. I originally enjoyed the idea of incorporating information-filled 
packets, however, after feedback and edits from my cooperating teacher, the packets became so simplified they could have been used in an elementary classroom. This caused a problem during teaching because some of the students quickly became bored. Bain (2004) explains the importance of promoting deep learning rather than just hitting the surface in order to help students become better thinkers. Since the packets lacked any form of challenging thought, the students didn't need to spend extra time thinking about or discovering new information and quickly lost interest.

The first page had definitions and students had to write in the words that belonged to each definition. These words included clay, kiln, firing, and glaze. In order to help students create connections to these words, I showed the images on the PowerPoint and passed around examples of glazed pieces. As a class we then discussed each of the terms as students filled in the correct answers.

The next section introduced different stages of clay. I thought back to the times I had taught clay in the past and remembered that students have a difficult time understanding the different stages just by discussing them or seeing images. Since according to Danielson (2009), reflections can help teachers develop a better understanding of successful methods, I decided to look back at previous lessons to determine the best way to teach the next section and adopted an idea I had during my high school placement. The night before class I had set out small sculptures I made in order to let one piece get leather hard and another sit until it became bone dry. This gave me examples to pass around the class that were small enough for them to handle but big enough for them to 
feel and see the differences between each stage. The students seemed to enjoy being able to have a small hands-on activity during the lesson.

The final part of the lesson was to explain different methods used when working with clay. While I originally wanted to do a demo at this point, I discovered that I was not allowed to bring clay into the main classroom and decided that moving the students would waste time. Instead, I showed images and drew examples on the board. When the lesson was over I gave students the opportunity to ask questions but no one raised their hand. Then we went through the packet as a class so I could get an idea of the students who understood the different terms and those who either didn't understand or didn't care. As I walked around the room, I asked a question from the packet and had the students respond as a group. Walking around the room gave me a chance to view the packets to see if all of the students wrote in answers. If the answers were written, but they weren't participating, this at least showed me that they were engaged but didn't want to verbally participate. Overall I felt good about the level of participation due to the amount of oral responses I received.

\section{Day 6}

I enjoyed this day because it gave everyone a bit of a break. The students had gone straight from one lesson to the next and the previous day was heavy with information. Since it was a Friday, my plan for this day worked out really well. The first part of class was dedicated to having the students make the newspaper molds for their mask. This was extremely helpful because it was one less thing they needed to worry about when returning from break. While the 
students enjoyed taping newspaper together, the second part of class seemed a bit more fun. I used a build your own crossword puzzle website and created a puzzle with different clay terms and methods that I had taught the previous day. This provided me with the opportunity to incorporate something fun but educational at the same time. I also decided to let the students sit with their friends as a way to praise their good behavior with a reward (Ahman, 2014). During the regular workdays, some of the students who were always well behaved, unfortunately, had to be moved away from friends to act as barriers between the troublemakers. For this reason, it was important for me to give them at least one day to work with a partner of their choice.

Although at times the class did get a bit loud, I was pleased with my decision to give them this break. I have learned that loud doesn't mean that students are misbehaving, but sometimes they are just enjoying learning. I made sure to walk around the classroom as they worked, and I rarely overheard discussions that were not about the assignment. The majority of conversations were students talking through the definitions and helping each other find the correct answers. If any conversations happened to be off topic, I would jump in and get the group back on task. This activity was also a way to incorporate collaborative learning, which can be a good way for students to challenge each other and assess their own learning (Bain, 2004).

\section{Day $7 / 8$}

I instructed students to work on their process diaries during the movie if they hadn't finished and I was able to help when they had questions. Most of the 
students were working very independently as they knew what needed to be completed. A few students, unfortunately, spent the time coloring on a worksheet, rather than focusing on their visual process diaries. These students claimed they were finished but left them at home. However, I later discovered they hadn't finished their diaries. It turned out that they were the same few students who never turned in the process diaries and rarely turned in previous assignments.

On day eight I reminded the students it was their last day to turn in their process diaries. Some of the students had taken theirs home over the weekend and brought them back while others took them to study hall and didn't bring them until after break. While this wasn't ideal, I was pleased to see two students who rarely complete anything, turn in this project. I am not sure if they turned this project in because they were emotionally invested or if they were finally interested in getting a grade. The ones I did receive I graded during my planning period in order to return them before they worked on their clay projects. I wanted the students to have a chance to refer to their drawings and my feedback before moving on to the next part of the unit.

\section{Day 9}

The students returned from break eager to start their masks. As they settled into the clay room I briefly went over the clay rules and reminded them to refer to their drawings from their visual process diaries. With more time I would have incorporated a productive review that further engaged the students such as putting them into groups and having them develop a quiz about the clay rules or 
having students summarize key points of what we learned (Jensen, 2005).

Unfortunately, we were already behind my original schedule and the students needed all the time they could get.

Before handing out the clay I demonstrated how to roll out a slab and form it to their mold in order to incorporate a visual explanation and differentiated instruction that would address visual learners (The Three Principles of UDL, 2014). I also showed a few attaching and carving techniques to review the slip and score methods and give the students a starting point. I opened up the floor and allowed students to ask questions so I could address common concerns. After answering the few questions I was asked, I reminded students I would be around to help as they worked.

Students went back to their seats and when they looked ready, meaning they were quiet with their hands in their laps, I called them one by one to grab their molds and their clay. The noise level quickly elevated as clay was being tossed and rolled out on tables and I weirdly fell back into my comfort zone. I found myself jumping from one table to the next and every time I turned to help another student I saw a new smile. Next thing I knew, I was instructing the students to clean up, and then things went slightly down hill.

It seemed that the students forgot how to follow directions. Tables that weren't dismissed were getting up while students from tables that were dismissed continued to work as their group started to clean. Too many people were up at once, the sinks quickly became crowded, and students were trying to throw away wet paper towels by tossing them over people standing in line. The 
noise also elevated and while I tried to give directions, it was a bit too chaotic for them to understand what I was saying.

When everything was cleaned up the students sat back at their tables while continuing their conversations. I turned off the lights to quiet them down and addressed the class with my disappointment. This was the first time I pulled out my teacher voice and I think they quickly figured out that I was not happy.

Since all of the students seemed to lack direction I decided I was slightly to blame for the chaos. Marzano and Marzano (2003) explain how one important component of classroom management is implementing rules and procedures and while these were in place, I realized I did a poor job articulating them to my students. My shortened schedule pushed me to try to shove too much information in a short amount of time, which left students without the ability to organize and process the new information about the clean up procedures (Jensen, 2005).

Although I knew my shortcomings in the situation, I also reminded myself that I was working with eighth grade students who were old enough to know right from wrong. These students know it is not acceptable to throw wet paper towels across the room or run around in a small space. They also knew that spraying another student with water was poor behavior. In hopes to make up for my mistake, I decided to readdress the rules the following day. I also explained that they would begin the class in silence as a consequence for their wild behavior and as an act of improving my classroom management. 


\section{Days 10-12}

Before going into the clay room the next day, I reminded the students there would be no talking, but I did give them an opportunity to earn time to talk at the end. I was pleased to see them focusing on their work, and with ten minutes left, I let them talk to their neighbors. The cleanup was much smoother this day and made I sure they knew how proud I was. By giving the class positive attention for good behavior I was able to incorporate more positive reinforcement, which would encourage students to continue making good decisions. Ahmann (2014) believes giving positive attention to good behaviors help students continue to make good choices that eventually develop into habit.

The following few days went by in a blur, and I am sure I got more than my normal day of exercise during this time. The students were eagerly adding details to their masks as I flew from one student to the next to help. I also encouraged the class to experiment, rather than wait for me to help. I explained that the best way for them to learn was to play around with the clay to discover techniques that were successful for them. This was also a way for me to reinforce the idea of allowing and encouraging mistakes by pushing students to indulge in the ways art is intended by experimenting, exploring, and being creative (Hurwitz \& Day, 2007). While a few students still had trouble making any decision without my approval, I was pleased to see the majority working independently.

\section{Day 13}

Today was my last day of student teaching, which meant it was also the last day for students to work. Knowing there wouldn't be time for critique, I tried 
to talk to all of the students at least once about their masks before they were done. As the students finished their work, I had them fill out a self-evaluation section on the rubric where they scored themselves in different categories. While having students create written reflections would have been a more productive way of discovering what they learned during the unit (Wenger, 2002), the selfevaluation portion was the best I could do given the timeframe. This process ended up being a little helpful however, because I reviewed student scores as I graded their masks.

While I didn't always interpret each mask the same way the student did, it gave me an idea of what areas students felt the most and least successful. This was important when determining the grade and helping to develop a growth mindset prescribed by Dweck (2007), by encouraging students in a positive way and describing how they improved and can continue to improve through the feedback that I gave them (Jensen, 2013). I was pleased with the overall outcome of the masks especially considering the small amount of time they had to work. The amount of creativity was wonderful and even the students who chose the same idiom created completely unique works.

\section{Discipline}

My personal horrors of teaching from day one of my university coursework centered on conversations about discipline. Of course when I thought of becoming a teacher, fragmented images of the enjoyable parts went racing through my mind. I focused on the fact that I would be able to hang out with kids all day while creating interesting lessons and teaching them about art. Somehow 
this fantasy world was also made up of perfect little angels that followed directions and fell in love with each and every art project. The first time discipline was discussed in class I was somewhat snapped from this fantasy while at the same time feeling confident in my ability to know the difference between being a friend and being friendly. This act is easier said than done when encountering the first miniature face of what used to be an innocent child. Over time I started to develop a teaching voice and picked up on techniques that I found to be successful.

When working on ones own discipline methods, merging into another person's classroom is difficult because it seems easier to adopt the rules and systems already in place. This continuity gives the students a sense of security (Jensen, 2005). During this particular study, my cooperating teacher used a basic three-strike system. She kept a clipboard on her desk, filled with a roster for each class and empty space next to the student's names. If a student misbehaved my cooperating teacher would start with a verbal warning. Any continued behavior meant a strike or written " $x$ " next to the students name. If she gave a second strike, the student's parent or guardian would receive and email and the third strike turned into a detention.

Although I felt this three-strike method had some inconsistencies, I found myself slowly adopting it while taking over the class because I knew it was something that was already familiar to the students. Over time I discovered that using strikes as a threat worked for some students; however, those who caused the most interruptions almost seemed to like the extra attention. For this reason I 
took advantage of this time to learn and to test out the theories I believed would be beneficial.

While my focus for this study was on the eighth grade class, I had large sections of written journal reflection on my sixth and seventh graders. This was fortunate because, as I look back on my experience, I realize each class informed my decisions for the next. Daily reflections became an important part of my process. Danielson (2009) argues that personal reflections can help a person avoid repeating poor decisions later, which is exactly what my reflections did for me. If I had success using a technique in one class, I would try it in another. Sometimes this would work and other times, due to the age difference, this repetition of technique would fail.

Before I begin to address discipline issues in my eighth grade class, I would like to reflect on a situation with $6^{\text {th }}$ graders that led me to specific decisions with my older troublemakers. In order to protect the privacy of the students, I used pseudonyms in place of their real names.

\section{Sixth Grade and Positive Reinforcement}

Generally being held captive at a desk facing the window rather than the rest of the class, Donnie seemed to have a difficult time staying still. Unaware of whether or not he had an Individualized Educational Plan (IEP), I watched as this sixth grader often wandered around the room when we wasn't supposed to and shouted out answers while my cooperating teacher was talking. This was my first observation of Donnie only after being warned that he was a difficult student who needed to be separated from the rest of the class. He apparently had the 
tendency to say inappropriate things to the other students, which made them uncomfortable, and my cooperating teacher felt that her only option was to create a separation.

While the choice to isolate seemed like an appropriate move at the time, I slowly discovered that this wasn't a short time thing, but, instead, his official new seating arrangement. He faced a window that was too high for him to see outside and he could only stare at a dingy white wall and a plant whose pot left paint flakes all over his desk. He was often scolded for turning around in his seat even during class discussion and from my perspective, he just wanted to be able to have a little bit of social interaction like the rest of the students. My goal for this class quickly became trying to find a way to reintegrate Donnie into the class without making other students uncomfortable.

When I first started to take over I received assistance from my cooperating teacher on how and who to discipline. This was helpful as I was still learning her strike system and wanted to run a well-managed classroom. Students generally did a good job listening, and if they shouted out during instruction it was mostly due to excitement and their desire to participate. After a few days of being in charge, I encountered a few issues with another troublemaker in the class who seemed to be testing what he could and couldn't get away with. While I tried to remain patient, my cooperating teacher instructed me to separate Martin from the class. He was moved to the front table, which acted as a place for my cooperating teacher to leave handouts and was a home for the binder students signed in and out of when going to the bathroom or getting a drink. Not only did I 
now have two students facing a wall without the ability to socialize, Martin also had a platform for distraction because students would come over to sign in and out or grab extra handouts throughout the period.

Martin seemed used to the distraction and even enjoyed the visit from different students; however, it quickly became an issue for me. Being the type of person who likes to have a space set aside for my things, an overcrowded desk makes my anxiety begin to bubble and eventually causes more issues. Whether or not Martin had concerns with his environment, I didn't feel right subjecting him to this arrangement. I soon discovered my next goal, which was to create an area for Martin or find a way to integrate him back into the class along with Donnie. Although student teaching kept me busy with a multitude of responsibilities, I spent a lot of time thinking about the positives and negatives of keeping students separated from the class. My cooperating teacher had clear reasons for setting up her classroom this way; however I felt this was the time for me to make my own decisions about discipline techniques, as I would not learn success or failures without testing out different theories. After much consideration I decided it was necessary for me to test out a method of positive reinforcement by, as Ahmann (2014) suggested, bringing positive attention to good behavior rather than attending to bad behavior. While I would typically run the class by saying positive things to students for behaving rather than scolding those misbehaving, I wanted to incorporate a reward system for Martin and Donnie. In order to do this correctly, I believed it was necessary for me to pay attention to what the two of them wanted. Of course the typical troublemaker 
aches for attention, and I knew Donnie and Martin enjoyed this as well, however I slowly realized what they really wanted was to interact with other students. This worked out well for me because it turned out that Donnie and Martin were friends. Since my CT did not want Donnie and Martin integrated back into the class in order to keep the other students comfortable, I figured the least I could do was let them sit together.

After making the decision, I started the next day of class as usual. The students worked on their packets and I gave further instructions. I became lucky this day because Donnie happened to be relatively calm. Students eventually started working on their projects and I told Donnie if he did a good job I would let him work with Martin. His eyes immediately lit up and as he shot back over to his desk he relayed the information to Martin. They both sat quietly and worked hard on their assignment for what might have been the entire period, but with about 20 minutes left in the class I allowed them to work together. I had never seen either of them so excited or focused. Due to the success of this method, I thought it would be a good idea to try it again the next day.

\section{Eighth Grade and Positive Reinforcement}

The success of positive reinforcement with the sixth graders influenced my decision to test it out with my most difficult eighth grade student, Maddox. Maddox wasn't difficult because he was rude, but instead he liked to shout out in class for attention. While he didn't have an IEP, he seemed to have a major issue staying focused. I constantly had to direct his attention back to the assignment and often explained how little time he had left to complete his work. 
I eventually completely took control over the eighth graders and started to teach my lesson, but Maddox shouted out during instruction so many times that my cooperating teacher sent him in the hallway. When he came back in I decided to have a conversation with him about being more respectful. I explained that most of the time he made great comments that contributed to the conversation but he needed to remember to raise his hand. Having this conversation worked for a few days, but once we moved into the clay room, things became difficult again.

\section{The Clay Room}

While the behavior could be attributed to the changing of rooms and materials, the size and set up of the clay room didn't help the situation either. The clay room, though separate from the main room was connected through a doorway and was much smaller than the regular classroom. A row of large cream-colored metal cabinets sat along the left wall as a cluttered black counter top took up space against the back wall. Toward the front of the room was a small slab roller used as a space to hold materials, a door to the hallway and two conjoining sinks. Most of the tables sat four students, and each table was so close to each other that the students' backs often touched. This made it difficult for the students to maneuver around the tables let alone give me space to reach each student when they needed help. This inability to move through the tight space caused an additional complication because one-on-one demonstration time with students is especially important with a difficult material like clay. For this reason, the rules in this room had to be a bit more restricting. Students were 
allowed to get up if they needed a tool or more water, but for the most part they needed to stay seated.

I had the opportunity to observe the management system used by my cooperating teacher for the $6^{\text {th }}$ and $7^{\text {th }}$ graders when they were working on a ceramics project, so for eighth graders I decided to adopt her system and make adjustments when necessary. One of the ways she managed the room was to dismiss tables, one or two at a time, to get their materials in the beginning of class. She would pick the quietest table of students first, which generally influenced them to start the class well behaved. At the end of class, she would switch off dismissing even tables and odd tables in order to allow enough room for everyone to move around with little contact.

The first day in the clay room was very hectic. Maddox consistently got out of his chair claiming he forgot to grab certain tools only to stop to chat with a friend while I was trying to help individual students. During cleanup, students were not following my dismissal instructions, but instead were getting up when they weren't supposed to or were continuing to work when they should have been cleaning. Considering all of the students were struggling, I decided this chaos was my fault due to lack of explanation or poor directions. Before I let the entire class leave I told them we would go over the directions the following day before getting out materials.

The next day I felt much better about my explanation and even asked students questions to make sure they listened and understood what was expected. I also took away the students' talking privilege for the first part of class 
under the instruction of my cooperating teacher. One of her rules in the class was that the ability to talk was a privilege, and the students needed to behave in order receive that privilege. By taking this away in the beginning of class it allowed the students to start the day in a calm way. In order to incorporate positive reinforcement, they would be able to gain their talking privilege at the end of class. This was a success as the students stayed focused and even talked quietly when they were allowed to talk again.

While the class overall was doing well, I was still having a bit of trouble keeping Maddox on task. He also spent time shouting out to his friend across the room. Since he was unfortunately already at a table by himself; I did not want to isolate him further by making him face away from the class. Instead, I decided to once again incorporate positive reinforcement by acknowledging his good behavior and providing him with an opportunity to work with his friend. While acknowledging good behavior didn't always show success, there was one day when I could tell it impacted him. At the end of class, Maddox did a great job putting away his materials and he cleaned his table so well it almost seemed to sparkle in the sunlight peeking through the window. At this point I stopped the entire class, directed them to observe his table, and explained that he did a fantastic job. I also told the class that his table was now the example for what each table should look like after cleanup. A huge grin crawled across his face, and he began to check other tables for me. This worked out well because all of the students got along with Maddox, so they didn't struggle following his directions. 
While this was a successful approach with Maddox, my favorite moment was the last of five workdays. He had been especially energized the day before possibly due to the sugary breakfast that was served, so when he came to class the following day I told him he would be allowed to work with his friend at the end of class if he behaved. To make sure Maddox understood my conditions, I told him he needed to stay at his table and focus on his mask without yelling across the room to his friend. He was also responsible for getting a significant amount of work done to his mask such as attaching and carving the rest of the facial features. Maddox, not surprisingly, ended up reacting in a similar way to Donnie by explaining to his friend they would have the chance to work together. He then went to his seat, stayed focused, and spoke to no one. I was so pleased with Maddox I told his friend to move to the other table so they could work together for the final fifteen minutes of class.

\section{Student Work}

The first examples of student work that came from my unit were of course, the visual process diaries. The diaries overall did not completely turn out as I had hoped but I had a few students who put in extra effort and other students who put in more effort than I had seen in the past. The students who excelled with this mini project incorporated fantastic sketches, told personal stories, and were creative with their overall layout. The student I wrote about earlier for example, used the idiom "pig out," and her visual process diary was an example of a student who excelled with this assignment. She created a colorful layout and incorporated detailed sketches for her mask (Figure D-1) that included notes 
about her ideas and colors she hoped to use. Her sketches also clearly influenced her final mask (Figure D-2).

Another student even related her idiom to her artwork. She chose the idiom "apple of my eye," and in her diary (Figure D-3) reflected on the ways her pets are very important. She also wrote that she would draw her pets every day, which helped her develop her artistic skills. Being a highly skilled artist, her diary was another example of an impressive work, because she included everything she was supposed to but also included great sketches on each page. Her mask sketches (Figure D-4) were also very detailed and included notes.

While the class didn't produce as many completed process diaries as I had hoped, the masks reflected a very different group of artists. One reason the diaries were lacking was because students were very unfamiliar with the process. While I explained that the diaries would be turned in for a grade, it is possible that students linked them to more of their familiar bell-ringer activities and didn't take them as seriously as I had hoped. The masks on the other hand were extremely impressive even with the short amount of time they had to work. The majority of class completed a mask and the only reason two of the students didn't finish was because they missed a few days of the unit and fell behind. Each mask was well thought out and very different from the next.

One of the most impressive masks was created by a student who chose the idiom "against the clock" in relation to his struggle with homework. He had strong ideas from the beginning and even included a very detailed sketch in his process diary (Figure D-5), which clearly influenced his final mask (Figure D-6). 
Even though he missed two days of the clay unit, he worked very hard to catch up and incorporated an impressive amount of detail. I also saw connections between his mask and those of Bjerkans in the way that he integrated the clock portion into his mask.

Another student who used the idiom "grass is always greener on the other side" truly thought outside of the box when creating her mask (Figure D-7). At first she struggled working with the clay but after spending a bit of time with this student, she discovered a technique that worked well. While she attached the necessary pieces, the majority of her mask was created using carving techniques. She was also the only one who didn't leave a single space as smooth clay but instead carved in details and textures from one edge to the next. While at first a viewer may not be able to guess her idiom, after spending time observing her work you begin to see the separation from one side to the other and the small details that make suggestions about her idiom. This was truly an exceptional piece.

\section{Summary}

This study was an examination of teaching methods used during my eightweek student teaching placement at a junior high school. During my placement I used arts-based educational research and the Frames to guide the creation of my unit. I also focused on the integration of student-centered teaching methods, visual process diaries, and positive reinforcement. While I had carefully planned my unit, I had to remain flexible in order to adjust for any unforeseen changes that took place while teaching. I originally wanted to spend more time discussing 
the artwork as well as the masks from various cultures but instead encountered hesitation from my students. A shift in my schedule created more challenges and I ended up having to make many changes. These changes shortened the amount of time students had to work on their visual process diaries and their masks. Even with the hiccups along the way, I still experienced some fantastic moments. The highlight of my teaching was the week of mask making. The students were engaged and I was impressed by their final pieces. I was also thrilled to see the success of my use of positive reinforcement and hope to see more success with this method in the future. 


\section{CHAPTER V}

\section{DISCUSSION AND RECOMMENDATIONS}

Through the experience of reflection during my eight-week student teaching placement, I was able to analyze the success and failures of my abilities as a teacher in relationship to the theories and methods I had researched prior to teaching. By applying these methods during my placement and completing daily reflections, I was able to find answers to my research questions. In order to discuss these answers, each research question will be addressed separately.

\section{Development}

The first research question I created was "In what ways did I develop as a classroom art teacher during an eight-week student teaching placement at a junior high?" According to oral feedback given by my university supervisor, I had great success creating rapport with my students. Weimer (2010) explains how rapport, or the development of positive relationships between the teacher and her students, can create higher levels of motivation, increased comfort, satisfaction with the class, and trust. In order to develop good rapport, Sears (2015) suggests a teacher must begin by getting to know the students, which I did by asking different questions about my students' interests and daily lives to discover more than just what I saw in the classroom. This process developed throughout my eight-week placement and the longer I was there, the more information I learned 
about each student. For example, as students completed their process diaries I would ask about their memories, how they related to idioms, and why they were important. I also spent time listening to them discuss their plans for after school activities like playing video games, going to basketball practice, or hanging out with a friend.

This development of rapport might be attributed to my desire to make connections with students regardless of how difficult it may have been due to the short time I had with them or some of the shyness I encountered. My concern with successes and failures to make connections with different students quickly became a reoccurring theme in my reflections. I wrote about how quickly I was able to create positive relationships with my sixth and seventh graders while the eighth graders were a bit more hesitant in the beginning. This can partially be attributed to the fact that I was not able to teach my own lesson plan to the eighth grade class until later on during my placement, and I lacked the time to arrange for a more individualized lesson. According to Sears (2015), creating an individualized curriculum can help a teacher build rapport with each student because they are able to learn comfortably and at their own pace. Rather than trying to make each student fit into one mold, an individualized curriculum creates challenges for students who quickly grasp the concept while giving enough time for those who struggle to learn the concept. While I spent time getting to know the range of my eighth graders' abilities, I was not able to introduce a fully individualized curriculum which would allow students to work at their own pace. When I did introduced the assignment, the lack of time caused 
me to push forward even when some students needed extra time to complete their process diaries and even their masks.

According to oral and written feedback given by my university supervisor, my abilities to create a well thought out lesson plan also developed as my placement progressed. I had many opportunities during my pre-service coursework to write a variety of lesson plans, and the student-teaching process allowed me to continue this process. The more I wrote plans, the better I felt about writing them and discovering what adjustments need to be made. My supervisor confirmed that my objectives became stronger and more specified and the day-to-day instructions were more direct and easier to understand.

I also spent less time writing lesson plans than I had in the past, which gave me more time to focus on other details like organization, teaching, and assessments. Farrell (2002) argued that although each teacher has a different way to prepare for lessons, planning was a great way for teachers to think about each step prior to teaching in order to make adjustments, create a map or guide for students, and have a record of what was taught each day. Farrell also explains that lesson planning is a great way for a teacher to build confidence because as they wrote the plan teachers thought through the steps of the lesson.

While reflecting on my experience as a whole, I would agree with comments made by my supervisor in regards to growth. Building rapport with students was very important to me and some students were more difficult to connect to than others. This experience however, taught me different ways to make connections with students I used to struggle learning about. Some students 
are shy and have a hard time opening up to teachers but I learned that it typically comes down to asking the right questions and giving them opportunities to talk about their interests. I also feel as though my skills in writing lesson plans have grown. I no longer spend as much time reworking objectives and assessments and I feel confident in my ability to create something interesting and unique for my students.

While I didn't receive direct comments about classroom management, I feel that this is another area I have grown. Classroom management is not something I had enough experience with prior to student teaching because my previous clinical experiences did not last long enough to develop a system. I student taught at a high school prior to the junior high however, the students at that level are more independent and classroom management was simple. During the junior high placement I found myself encountering moments I had never dealt with in the past such as every student needing to use the restroom at once or students getting into arguments. It may have been intimidating at first I eventually developed my own ideas based on research on how I would like to manage my future classroom.

\section{Successes and Failures}

The second research question in my study asked about the successes and failures of the methods and techniques used during my placement. I found this difficult to answer due to limitations on some of the methods I was hoping to

incorporate; however, I was able to address this question for those methods I did use which included: student-centered teaching, visual process diaries, allowing 
and encouraging mistakes, integrating of diverse and contemporary artists, and the use of positive reinforcement.

\section{Student-Centered Teaching}

The first important part of my lesson plan included the use of studentcentered teaching. It is my personal belief that students have lost their desire to learn because they are now pressured into knowing specific information instead

of being able to follow their own interests. According to Gardner (1987), studentcentered teaching allows the students to make choices to include their own interests, which makes the lesson more meaningful. This doesn't mean students get to pick the assignment, but rather allows them to incorporate personal stories and interests into their learning in order to discover new information about other topics.

If I had the opportunity to get to know the students earlier on, I would have been more successful with student-centered teaching; however, I did accomplish some student-centered techniques. For example, my eighth grade mask unit was flexible enough for students to make decisions based on what they found most interesting. By allowing students to pull from their personal memories when creating their masks, I provided opportunity for them to use their own backgrounds as inspiration. I also incorporated a Pictionary game that put the students at the center of learning and allowed opportunity for students to use their background knowledge when making decisions. Garion (2002) argued that when teachers can start with the student rather than themselves they can create 
relevant experiences for students, especially when they can integrate their own cultural backgrounds.

While not all students dug deeply into their personal backgrounds, a few shared very personal stories. One of my students, for example, chose the idiom " a leopard can't change its spots." In her visual process diary she wrote about how she had learned that she has to accept herself for who she is and appreciate her own background. While she didn't include information about her background, I was pleased to see her integrating past experiences. By allowing her to choose an idiom that connected to her personal story, she created a meaningful reflection and spent time developing nice detail in her final mask. At first she scoffed at the idea of working with clay, but once she started she didn't stop until she was finished and she seemed to forget about her initial reaction.

Integration of flexibility within the visual process diaries was another moment I saw success in the student-centered approach. By giving students the ability to make their own decisions with this project, students became more capable of asking their own questions, discovering answers, and finding solutions to different problems. According to Strickland (2012), students need to be able to make choices in their educational journey in order to find ways to solve problems and stay interested in learning. While not as many students turned in their visual process diaries, as I would have liked, the submitted diaries shoed success with the student-centered teaching approach because the students put more effort in this assignment than they had with previous sketchbook assignments given by my cooperating teacher. 


\section{Allow and Encourage Mistakes}

Another method I tried to incorporate into my planning was to allow and encourage mistakes. With more time I would have hoped to give students the opportunity to not only reflect on what they made and why, but also resubmit their assignment for a better grade after giving them written and oral feedback.

According to Dweck (2007) this would have assisted in building a growth mindset in my students rather than a fixed mindset, because effort and learning would have taken precedence over the final product.

Due to the limitations of my study, I was not able to provide students with the chance to resubmit because I was only at this placement for eight weeks and ran out of time. I did incorporate this idea, however, in other ways. When the students played "Pictionary" for example, I encouraged them to at least try, and if they failed or were unable to draw the idiom, they could try a new one. This was my way of telling the students it was acceptable to make a mistake or not be able to accomplish their goal on their first try. This also provided my students with the opportunity to be more creative. Cleese (n.d) has argued that people who are not afraid of mistakes are more creative because they are willing to try new things. This is especially important in an artwork where creativity is a main component of the class.

I also integrated this approach when students began working with clay. I gave two brief class demonstrations on the basics of using the clay, but pushed my students to experiment with hand building techniques and different ways to create their facial forms. This was partially due to my inability to get around to 
each student when they needed help but mostly to push them to experiment. By encouraging experimentation, I was able to give my students time to work through their problems. According to Bain (2004) this type of practice is something that the best teachers do because it creates an environment where students aren't afraid to make mistakes, and instead they challenge themselves to come up with their own answers.

\section{Arts-Based Educational Research}

Creating my unit plan using arts based educational research (ABER) was another essential part of the study. While I attempted to incorporate this thinking into class discussion, I had a difficult time getting students to respond. Some students made connections between Bjerkan's masks and idioms or personal stories during our discussions, but the majority of the class did not actively participate. Although the integration of ABER was not very successful due to lack of time to discuss the artist and complete individual research, I do feel that it can be achieved in my future classroom. Bucholz \& Sheffler (2009) describe multiple ways to create a participatory classroom environment and some of these were out of my control. For example, creating a neat and organized classroom can help students feel comfortable because the classroom becomes a space that is easily accessible and safer for all students. Considering the space I taught in was not mine, I was unable to create my ideal environment. While the classroom I was in was organized, there was a lack of space for me to display items like teacher examples, student examples, and supporting visual materials. I was also instructed to keep certain materials out on desks, regardless of whether or not 
students needed them that day. This caused confusion and distraction for the students. Finally, students often had a hard time finding materials because I continuously had to move them due to lack of space.

Another argument made by Bucholz and Sheffler (2009) regarding the creation of a welcoming environment is the need to introduce routine class meetings. These meetings can be made of small or large groups of students who work together to solve a problem. Working in groups teaches students how to socialize by respecting the opinions of their peers and by learning how to verbalize their own ideas. Prior to my lesson, I hadn't witnessed any form of group work or discussion, which explains why students were not as confident in expressing their opinions when looking at Bjerkan's masks.

In order to change the dynamic in my future classroom, I will first create an environment that is visually appealing. I can do this through decoration, display of images of artists' work, neatness, and organization as Bucholz \& Sheffler (2009) describe. I also want to create an environment where students feel comfortable discussing their opinions in order to get them more actively involved in analyzing artwork. By incorporating small and large group work from day one through the final day where students work together to find answers, students will become more comfortable speaking in front of their peers during class discussion without fear of rejection or embarrassment.

\section{Visual Process Diaries}

The integration of visual process diaries was also important to my unit. While there were some successes with student-centered teaching in this project, 
I unfortunately felt it was not as successful as I had originally intended due to lack of time. Visual process diaries typically include experimentation with a range of media, writings, and reflections that work through ideas for a final project. (Board of Studies NSW, 2003). These diaries act as a way for teachers to access the progress of their students and provide in-progress feedback. Considering NSW students have an extended amount of time to work through their journals by incorporating different lessons, I knew I would have to alter this idea to fit into my classroom. Rather than giving the students an entire semester for experimentation, they would have to use this time to develop an idea for one project.

Although I tried to encourage the students to incorporate different materials within their visual process diaries in order incorporate different colors and textures while learning about new media, few students went beyond the use of colored pencils and markers. This may be attributed to the comfort level of colored pencils verses paint and collage and the fear of making a mistake. Bartel (2015) argues that students who have the freedom to do what they want often choose something they already know. Rather than choosing something new and taking a risk, students like to keep within their comfort zones. Bartel believes providing limits within freedom to choose can help guide the students to try something new. For this reason, it is possible that I gave the students too many choices, which essentially made them stay within their comfort zones.

Even though the visual process dairies were not a complete success, some of the students enjoyed the diaries, and it was a good way for students to 
plan for their ceramic mask beyond a typical sketch. The students who completed their process diaries knew exactly where to start when moving into the clay room. The students who struggled developing ideas in the clay room were the same students who had not completed their visual process diaries. While I did my best to give each student extra time to complete their diaries, a few lost interest. One of these students often showed up late to class if at all which constantly put them behind. Another student who failed to complete his diary was a student who failed to complete any projects in the past.

I also now know what adjustments I need to make in my future classroom.

Rather than using the diary for one project, I would like for it to be something they work on throughout the semester. This would give them more time to experiment with different ideas the students are interested in prior to starting a main project and push them to explore various new materials. I will also create a more focused guide for the use of materials in my assessments. For example, one of my assessments may be based on the creative use of different materials or the need for students to use a certain amount of materials.

\section{Integration of Diverse and Contemporary Artists}

The integration of diverse and contemporary artists is also very important to the teaching methods I wish to continue using in the future. I typically like to focus on multiple artists in my lessons. As Morgan (2012) recommended, I try to find artists who represent diverse cultures and genders in order to give my students perspectives beyond that of the typical white male curriculum. While Morgan argues that females lack representation in the classroom and can be 
considered an integration of diversity, I would have liked to have integrated more artists. Since I only had time to focus on one artist, I did my best to integrate other cultures by briefly discussing masks used in different regions, by different people, and at different times throughout history. I have no way to fully discuss the impact it had, if at all, on my students because this part of the lesson was so brief due to time limitations and my inability to have the students create a final reflection on the unit. However, I plan on making appropriate adjustments in my future classroom by spending more time focusing on different artists and incorporating more time for students to reflect.

\section{Positive Reinforcement}

The final method introduced during this study focused on discipline methods. Ahmann (2014) has explained that the use of positive reinforcement allows the teacher to focus on positive behaviors and rejects negative ones. While I learned about positive reinforcement during my university coursework, I had not been able to try out this approach until my student teaching placement. Overall, I felt the use of this method was one of my most successful moments during the study, possibly due to the emotional connection that developed. This process allowed me to connect with students in a positive way that I was unable to do in shorter clinical experiences. Giving attention to good behaviors as Glasser (1999) suggests, shifted the behaviors and attitudes of Donnie and Maddox, the two students I struggled with in the beginning. Rather than punishing them for acting out, I gave them the opportunity to work with friends if the behaved as a way to reward the boys for following directions. I also was sure 
to make positive comments when they followed instructions rather than giving them attention when they acted out.

\section{Recommendations for My Own Teaching}

Overall I wish to continue to incorporate the previous teaching methods within my future classroom in order to have a more realistic idea of what can be successful and what adjustments need to be made as I continue teaching. That being said, I believe I had some success with methods such as student-centered teaching, visual process diaries, and positive reinforcement; however, I will need to make changes with all methods used during my career. Those methods that showed success will need to be integrated further and those that were hardly integrated deserve another chance.

My biggest issue seemed to be the lack of time I had with my students, which created barriers when getting to know them and creating a more appropriate learning environment. For my future classroom I will have more control over the timeframe, which will give me further opportunity to learn about my students and the ability to create lessons accordingly. I will also be able to create more time for critical and historical discussions about artwork so students can learn beyond art making and apply new concepts to their work.

I will also create an environment where students are not afraid to make mistakes by providing time to resubmit projects and reflect on decisions they made. This will help students understand that the final project is not always the most important thing but instead focus on what they learned throughout the process. With a focus on taking risk and allowing for mistakes, my hope is that 
students will open a new mode of creativity and no longer be focused only on the "right" answer, but instead, develop a growth mindset that values effort as described by Dweck (2012). This environment will also be created through the integration of visual process diaries throughout the entire quarter or semester rather than for one project. The diaries will be a place where students can develop ideas and experiment with different media in order to figure out what would work best. Students can also reflect on what they are learning and why they want to make certain choices which will give me a better understanding of their goals.

While I had no way of gauging what sort of impact the integration of diverse and contemporary artists had on my students due to the lack of time and lack of reflection, I still strongly believe in the importance of continuing this practice in my future classroom. This will give my students a chance to see a multitude of perspectives beyond what is typically seen in the classroom and learn about more possibilities within the art world.

\section{Recommendations for Future Student Teachers}

Student teaching may not be the ideal environment for everyone on his or her path to becoming a teacher. Every student will be placed at a different location and some will feel more comfortable in their placements than others. Regardless of placement however, this is the time for student teachers to discover who they are as teachers. The first recommendation I have for future student teachers is to do the best with what they have and take any opportunity to experiment with teaching methods, techniques, and lessons they are curious 
about or believe will be the most successful. This process will help them discover what methods are most effective and what changes can be made in the in the future.

Since I often feel that teaching is one giant exploration because of the ongoing adjustments that are made according to individual students and classroom dynamic, I also believe it essential for student teachers to reflect each day on successes and failures of methods used along with any moment the student teacher feels is relevant. These reflections must go beyond what the lesson was and dig into personal fears, favorite moments, and honest representation of how they feel about the entire situation. In order to truly make their reflections worthwhile, they must also connect their thoughts with research in order to discover ways they can improve and decide why certain situations are happening in their classroom.

Although, honesty for me was tough at first, I discovered that the more honest I was about the situation, the more I learned about my personal strengths and weaknesses. The reflections also gave me more confidence due to personal awareness because I knew what adjustments to make and could use my strengths to my advantage. The best parts of my reflections however, were the moments that revealed the things I valued most as a teacher. I used to think I knew what was most important, but as I looked back on my writings I discovered themes and uncovered truths about myself that originally were not available to my conscious mind. 


\section{Recommendations for Future Study}

There are two recommendations for future study. The first is for teachers to use audio or video recordings rather than depending on personal reflections and feedback from colleagues. Cox (2016) explains how recording video of what takes place in the classroom creates an unbiased view. Teachers can then see what really happened rather than only analyzing their perspective and unintentionally ignoring important information. While I attempted to remain neutral during my analysis, my reflections were the prime source of my data and it would have been interesting to look through an alternative lens.

Since this study taught me valuable information about my abilities and various teaching methods, I also recommend this reflective process for teachers. For this study I did not have complete control over my use of time and was unable to integrate everything I had originally planned. However, teachers typically have their own classroom and are in charge of the schedule and the methods they wish to integrate into lessons and management. This reflective process would help teachers better understand how to avoid repeating ideas that have not been successful while embracing those that truly create the best learning environment for students. 


\section{REFERENCES}

Ahmann, E. (2014). Encouraging positive behavior in "challenging" children: The nurtured heart approach. Pediatric Nursing, 40(1), 38-42.

Alexenberg, M. (2008). Autoethnographic identification of realms of learning for art education in a post-digital age. International Journal Of Education Through Art, 4(5), 231-246.

Ambrose, S. A., Bridges, M.W., DiPietro, M., Lovett, M.C., \& Norman, M.K. (2010). How learning works: 7 research-based principles for smart teaching. San Fransico, CA; John Wiley and Sons Inc.

Anderson, T. (2014) Climbing Kilimanjaro: Narrative and autoethnographic research. In K. Miraglia \& C. Smilan (Eds.), Inquiry in action: Paradigms, methodologies, and perspectives in art education research (pp. 88-98). Reston, VA: National Art Education Association.

Andrews, B.H. (2010). Student ownership: Learning in a student-centered art room. Art Education, 63(4), 40-46.

Contemporary art in context. (2016). ART21. Retrieved from http://www.art21.org /learn/tools-for-teaching/on-contemporary-art/contemporary-art-in-context Bain, K. (2004). What the best college teachers do. Cambridge, MA: Harvard University Press. 
Barone, T. \& Eisner, E. (2012) Arts-based educational research. Los Angeles, CA: Sage Publications.

Bartel, M. (2015). Eleven classroom creativity killers. Retrieved from https://www.goshen.edu/art/ed/creativitykillers.html

Bjerkan, P. (2011). Ceramic maskwoman aka Peggy Bjerkan. Ceramics and pottery arts and resources. Retrieved from http://www.veniceclay artists.com /ceramic-maskwomanaka-peggy-bjerkan/

Board of Studies NSW. (2003). Visual arts Years 7-10 syllabus. Retrieved from http://www.boardofstudies.nsw.edu.au/syllabus_sc/visual-arts.html

Brandt, R. (1987). On assessment of the arts: A conversation with Howard Gardner. Educational Leadership, 45(4), 30-34.

Bucholz, J.L. \& Sheffler, J. (2009). Creating a warm and inclusive classroom environment: Planning for all children to feel welcome. Electronic Journal for Inclusive Education, 2(4), 1-14. Retrieved from http://corescholar. libraries.wright.edu/cgi/viewcontent.cgi?article=1102\&context=ejie Chinese Masks and Color Meanings. (2014). Retrieved from http://traditions. cultural-china.com/en/16T9161T13273.html

Cox, J. (2016). Teaching strategies: The value of self-reflection. Retrieved from http://www.teachhub.com/teaching-strategies-value-self-reflection

Cubukcu, Z. (2012). Teachers' evaluation of student-centered learning environments. Education, 133(1), 49-66. 
Danielson, C. (2013). The framework for teaching: Evaluation instrument. Retrieved from http://www.hcpss.org/f/aboutus/teacher_eval/teach_eval_ guide.pdf

Danielson, L. (2009). Fostering reflection. Educational Leadership,66(5).

Retrieved from http://www.ascd.org/publications/educationalleadership/feb09/vol66/num05/Fostering-Reflection.aspx

Delacruz, E. \& Bales, S. (2010). Creating history, telling stories, and making special: Portfolios, scrapbooks, and sketchbooks. Art Education, 63(1), 33-39.

Dewey, J. (1916). Democracy and education: An introduction to the philosophy of education. NY: The Macmillan Company

Dweck, C. S. (2007). The perils and promises of praise. Educational Leadership, 65(2), 34-39. Retrieved fromhttp://www.ascd.org/publications/educationalleadership/oct07/vol65/num02/The-Perils-and-Promises-of-Praise.aspx

Edwards, S.L. (2014). Using personal narrative to deepen emotional awareness of practice. Nursing Standard, 28(50), 46-51.

Eisner,E. (2013). Educational objectives-Help or hindrance? The Curriculum Studies Reader. NY: RoutledgeFalmer

Eldridge, L. (2012). A Collaged reflection on my art teaching: A visual autoethnography. The Journal of Social Theory in Art Education, 70-79.

Farrell, T. S. (2002). Methodology in Language Teaching: An Anthology of Current Practice. Cambridge, NY; Cambridge University Press 
Felder, R. M. (n.d.) Student-centered teaching and learning. Retrieved from http://www4.ncsu.edu/unity/lockers/users/f/felder/public/StudentCentered.html

Freeman, N. \& Sanger, D. (1993). Language and belief in critical thinking: Emerging explanations of pictures. Exceptionality Education Canada,3(3), 43-58.

Garion, C. R. (2002). Contemporary issues in art education. Upper Saddle River, NJ: Pearson Education Inc.

Gay, G.(1992). Effective teaching practices for multiculturalism classrooms. Multicultural Education for the $21^{\text {st }}$ Century. Washington, D.C.: National Education Association

Glasser, H. \& Easley, J. (1999). Transforming the difficult child: The nurtured heart approach. Tucson, AZ: Macmillan Publishing.

Greenwood, J. (2012). Arts-based research: Weaving magic and meaning. International Journal of Education \& the Arts, 13(interlude 1). Retrieved from http://www.ijea.org/v13i1.pdf

Gude,O. (2013). New school art styles: The project of art education. Art Education. Retrieved from https://naea.digication.com/omg/New_School _Art_Styles_the_Project_of_Art_Education

Hidalgo, N.M. (2012). Multicultural teacher introspection. Social Foundations and Multicultural Perspectives in Education. United States: University Readers Inc. 
Halprin, L. \& Burns, J. (1974). Taking part: A workshop approach to collective creativity. Cambridge, MA: The MIT Press, Inc.

Holmes, M. (2002). The art diaries. Penn State News. Retrieved from http://news.psu.edu /story/140660/2002/01/01/research/art-diaries

Hurwitz, A. \& Day, M. (2007). Children and their art: Methods for the elementary school. Belmont, CA: Thomas Wadsworth Corporation

Illinois Report Card. (2015). xxxx Junior High. Retrieved from http://www.illinoisreportcard.com/School.aspx?schoolld=17064005026100 4

Jensen, E. (2001). The science of the arts. Arts in Education. Retrieved from https://www.nassp.org/portals/0/content/53915.pdf

Jensen, E. (2005). Teaching with the brain in mind. Alexandria, VA: ASCD.

Jensen, E. (2015). How poverty affects classroom engagement. Educational Leadership. 70(8) pp.24-30.

Johnson, B. (2009). Student feedback helps teachers grow. Edutopia. Retrieved from http://www.edutopia.org/student-feedback-accountability-teachers Jones, J. (2016). John Cleese on the importance of making and embracing mistakes. Open Culture: The Best Free Cultural \& Educational Media On The Web. Retrieved from http://www.openculture.com/2016/01/johncleese-on-the-importance-of-making-and-embracing-mistakes.html Klein, S.C. (2014). Action research in art education: Principles and possibilities. In K. Miraglia \& C. Smilan (Eds.), Inquiry in action: Paradigms, 
methodologies, and perspectives in art education research (pp. 44-56). Reston, VA : National Art Education Association

Ladson-Billings, G. (1994). The dreamkeepers: Successful teachers of African American children. San Francisco, CA: Jossey-Bass.

Learning objectives. (2014) The glossary of education reform for journalists, parents, and community Members. Retrieved from http://edglossary.org /learning-objectives/

Learning standards. (2014). The glossary of education reform: for journalists, parents, and community members. Retrieved from http://edglossary.org /learning-standards/

Leigh, S.R. (2012). The power of the sketch(book): Reflections from high school English students. Journal of Adolescent \& Adult Literacy, 55(6), 539-549.

Marshall, J. and D'Amado, K. (2011). Art practice as research in the classroom: A new paradigm in art education. Art Education, 64(5), 12-18.

Marzano, R. J. \& Marzano, J. S. (2003).The key to classroom management. Educational Leadership 61(1) 6-13

Marzano, R.J. \& Toth, M. D. (2016). Teaching for rigor: A call for a critical instructional shift. Learning Sciences Marzano Center. Retrieved from http://www.marzanocenter.com/essentials/

Mask (Kanaga). (2016). Retrieved from http://www.metmuseum.org/art/ collection/search/315061 
McConell, A.R. (2010). Reflection critical for self-improvement. Psychology Today. Retrieved from https://www.psychologytoday.com/blog/the-socialself/201009/ reflection-critical-self-improvement

Morgan, H. (2012). Gender, racial, and ethnic misrepresentation in children's books: A comparative look. In P. Hoff \& M. Nur-Awaleh (Eds), Social Foundations and Multicultural Perspectives in Education (pp.351-358 ). San Diego, CA: Cognella Publishers.

NAEA. (2014). Position statement on pre-service education and its relationship to higher education. Retrieved from file://Users/Addie/Downloads/PPS\%20\%20Position_Statement_on_Pre-service_Education_Adopted_March_2011\%3B_Reviewed_and_Revised_April_2014-.pdf

Osterman, K.F. (1990). Reflective practice: A new agenda for education. Education and Urban Society. Retrieved from http://isites.harvard.edu /fs/docs/icb.topic872691. files/Osterman1990pp133-152.pdf

Pajares, F. (2003) Educational psychology: A century of contributions. Retrieved from http://www.uky.edu/ eushe2/Pajares/PajaresJames.PDF

Pike, A. N. (2016). Greek theater mask facts. Retrieved from http://entertainmentguide.local.com/greek-theater-mask-1276.html

Pilecki, T. \& Sousa, D. (2013). From STEM to STEAM: Using brain-compatible strategies to integrate the arts. Thousand Oaks, CA: Corwin.

Rosenberg, M. \& Thurber, F. (2007). Gender matters in art education. Worcester, MA: Davis Publications. 
Savage, S. L, Cannon, D., \& Sutters, J.P. (2015). The yellow brick road to licensure: Mentoring student teachers through the practicum experience. Art Education, 68(4), 22-27.

Schank, R.C. (1995). What we learn when we learn by doing. Retrieved from http://cogprints.org/637/1/LearnbyDoing_Schank.html

Shaw, L. J. (n.d.) Humanistic and social aspects of teaching. Retrieved from http://www.edu-design-principles.org/docs/educational_philo.pdf

Strickland, M. (2012). More than a test score: Strategies for empowering youth at risk. Lanham, MD: Rowman \& Littlefield Publishers, Inc.

The Future of Teaching. (2014). Virginia Journal of Education. Retrieved from http://www.veanea.org/home/2223.htm

The Three Principles of UDL. (2014). The National Center On Universal Design For Learning. Retrieved from http://www.udlcenter.org/aboutudl /whatisudl /3principles

United States Census. (2014). QuickFacts Normal town Illinois. Retrieved from http://www.census.gov/quickfacts/table/PST045215/1753234

Vasconcelos, E. F. S (2011). "I can see you:" An autoethnography of my teacherstudent self. The Qualitative Report, 16(2), 415-440. Retrieved from http://www.nova.edu/ssss/QR/QR16-2/vasconcelos.pdf

Weimer, M. (2010). Building rapport with your students. Faculty Focus: Higher Ed Teaching Strategies From Magna Publications. Retrieved from http://www. facultyfocus.com/articles/teaching-and-learning/building-rapport-with-yourstudents/ 
Wenger, G. (2002). The visual process diaires of New South Wales, Austrailia. Research at Penn State, Winter 2001. 
APENDIX A

\section{LETTER OF ASSENT}


Dear Visual Arts Student:

I am a graduate student in the Art Education program at Illinois State University in Normal, Illinois. I wish to conduct research during my student teaching placement at your school to examine my own progress as a teacher. Your school has agreed to allow me to proceed with my research. However, I am asking for your assent to be involved in my study. I will teach a unit plan to your class and provide feedback to you and give assessments. I will also give you short pre/post tests to measure what you learned from the unit but these tests will not be graded and will not affect your final grade. I will review your unit responses and reflect upon my efforts at successfully presenting and teaching the material that may have led to your successful completion of the unit.

The research will include photographing selected images of your artwork and reflections and approved sections of your process diary. You may refuse to allow photographs of any of your work and reflections. Your grade will not be affected by choosing to participate or not to participate and you may withdraw from the study at any time without penalty.

In order to insure confidentiality, your name will not be included in photographs and pseudonyms will be used for any and all participants. The results of the research study may be published in academic journals, but names will not be used and the teachers', students', and school's confidentiality will be protected.

If you have any questions or concerns about your participation you may contact me. Thank you for your time and consideration.

Sincerely,

Adrielle Schneider

\section{Statement of Assent}

I have read the above information and have received answers to any questions I asked. I assent to the inclusion of photographs of my artwork, pages of my visual journal, and reflections that I have selected to be used in this research. My assent allows my artwork, visual journal pages, and reflections to be: reviewed by the researcher; presented at academic conferences related to the research; included within the researcher's published articles; and presented at teacher workshops. I understand that my name will not be made public.

Your Name (printed)

Your Signature

Date: 
APPENDIX B

LETTER OF CONSENT 
Dear Parent/Guardian of a Visual Art Student:

I am a graduate student in the art education program at Illinois State University in Normal, Illinois. I wish to conduct research during my student teaching placement at your students' school to examine my own progress as a teacher. The school has agreed to allow me to proceed with my research however I am asking for your permission for your student's involvement in my study. I will teach a unit plan to your student's class. I will provide pre/post tests to see if and what your student learned. This will not count as a grade or affect their grade. I will review students' unit responses and reflect upon my efforts at successfully presenting and teaching the material that may have led to students' successful completion of the unit.

The research will include photographing selected images of your students' artwork and reflections and approved sections of his/her process diary. You may refuse to allow photographs of any of your students' work and reflections. His/her grade will not be affected by choosing to participate or not to participate and you may withdraw them from the study at any time without penalty. The results of the research study may be published in academic journals, but names will not be used and the teachers', students', and school's confidentiality will be protected.

If you have any questions or concerns about your participation you may contact me. Thank you for your time and consideration.

Sincerely,

Adrielle Schneider

\section{Statement of Permission}

I have read the above information and have received answers to any questions I asked. I give my permission for the inclusion of photographs of my student's artwork, pages of their visual journal, and reflections that they have selected to be used in this research. My permission allows my students' artwork, visual journal pages, and reflections to be: reviewed by the researcher; presented at academic conferences related to the research; included within the researcher's published articles; and presented at teacher workshops. I understand that my students' name will not be made public.

Your Students Name (Printed)

Your Name (printed)

Your Signature

Date: 


\section{APPENDIX C}

\section{IDIOMS PACKET}

\begin{tabular}{|c|c|}
\hline \multicolumn{2}{|l|}{ Possible Idioms } \\
\hline Tm All Ears & You have my undivided attenton \\
\hline A Penny for your thooghts & A way of asking what somoone is thinking \\
\hline Actions speak louder than words & People's intentons can be judged betior by what fhey do than what they say. \\
\hline At the drop of a hat & Whout any hesiation; instantly. \\
\hline Best Thing since sloed bread & A good irvention or innovation. A good idea or plan. \\
\hline Bhe off more than you can chew & To take on a task that is way to big. \\
\hline CanY judpe a book by its cover & Cannot judge something primarly on appearance. \\
\hline Cry over spit mik & When you complain about a loss from the past. \\
\hline Hit the Nail on the Head & Do or say something exacty right \\
\hline Let the Cat out of the bag & To share informafon that was previously concosaled \\
\hline St. on the Fence & This is usod when someone does not want 60 choose or make a decision \\
\hline Once in a Blue Moon & Happens vory rarely \\
\hline The last straw & The final problem in a sories of problems \\
\hline Hear it on the grapevine & To hear rumors about something or someone \\
\hline A Loopand Cant Change Hs Spots & You cannot charge who you are. \\
\hline A Penny Saved ls A Penny Eamed & By not spending money, you are saving money (Ittle by fit:e \\
\hline Against The Clock & Rushod or short on time \\
\hline Apple of my Eye & Somoone who is cherished above all ethers \\
\hline Bhe your tongue & To avoid taking \\
\hline New York Min.be & A minute that sooms to go by quickly, especialy in a fast paced emvitonement \\
\hline On Pins And Needes & Anvious or nervous, especialy in anticipation of something \\
\hline Out On A Limb & When somecone puts themsef in a risky siduation \\
\hline Pig O.t & To eat a lot and oat ît quickly \\
\hline Put a sock in ît & To bell noisy person or a group to be quiet \\
\hline Raining Cats and Dogs & A very loud and noisy rain storm \\
\hline Change of Heart & Changod your mind \\
\hline Ants in your pants & Not able to sit stil \\
\hline Busy as a Bee & Actively involved \\
\hline Cool as a cucumber & Calm \\
\hline Crossing your fingers & Wshing good luck \\
\hline Put on Your Thinking Cap & Concentrabe and work hard to think about something \\
\hline When Pigs fy & Somothing that will never hapgen \\
\hline Nuts and Bots & Details \\
\hline Sounds like a broken record & Repeating the same things over and over \\
\hline Think outside the box & Think dillenently \\
\hline Chicken & Coward/Afraid of doing things \\
\hline Down to Earh & Realstic \\
\hline Give sombone a hand & Help somoone \\
\hline Rings a bell & Sounds familar \\
\hline Rise and Shine & Wake up \\
\hline A red flag & A sign that makes someonelsomething unteliable \\
\hline Couch Potato & Someone who is lazy or sits on the couch al the fime \\
\hline Grass is greener on the other side & What we don' know will a' ways scem betier \\
\hline In a nutshel & Briefly, summary \\
\hline Out of this world & So good, great \\
\hline Rain or Shine & Regardless of the woather \\
\hline Under the wasther & Not feoing good \\
\hline $\mathrm{Cr} y=0 \mathrm{li}$ & To Lie \\
\hline Two peas in a pod & Very dentcal/ similar \\
\hline Zp your ligs & Be quiet \\
\hline Seect Tooth & Someone who loves sweets \\
\hline Sharp as a tack & Very smart \\
\hline Hit the Hay & Go 20 bed \\
\hline
\end{tabular}

Figure $C-1$. Second page of idioms packet. 


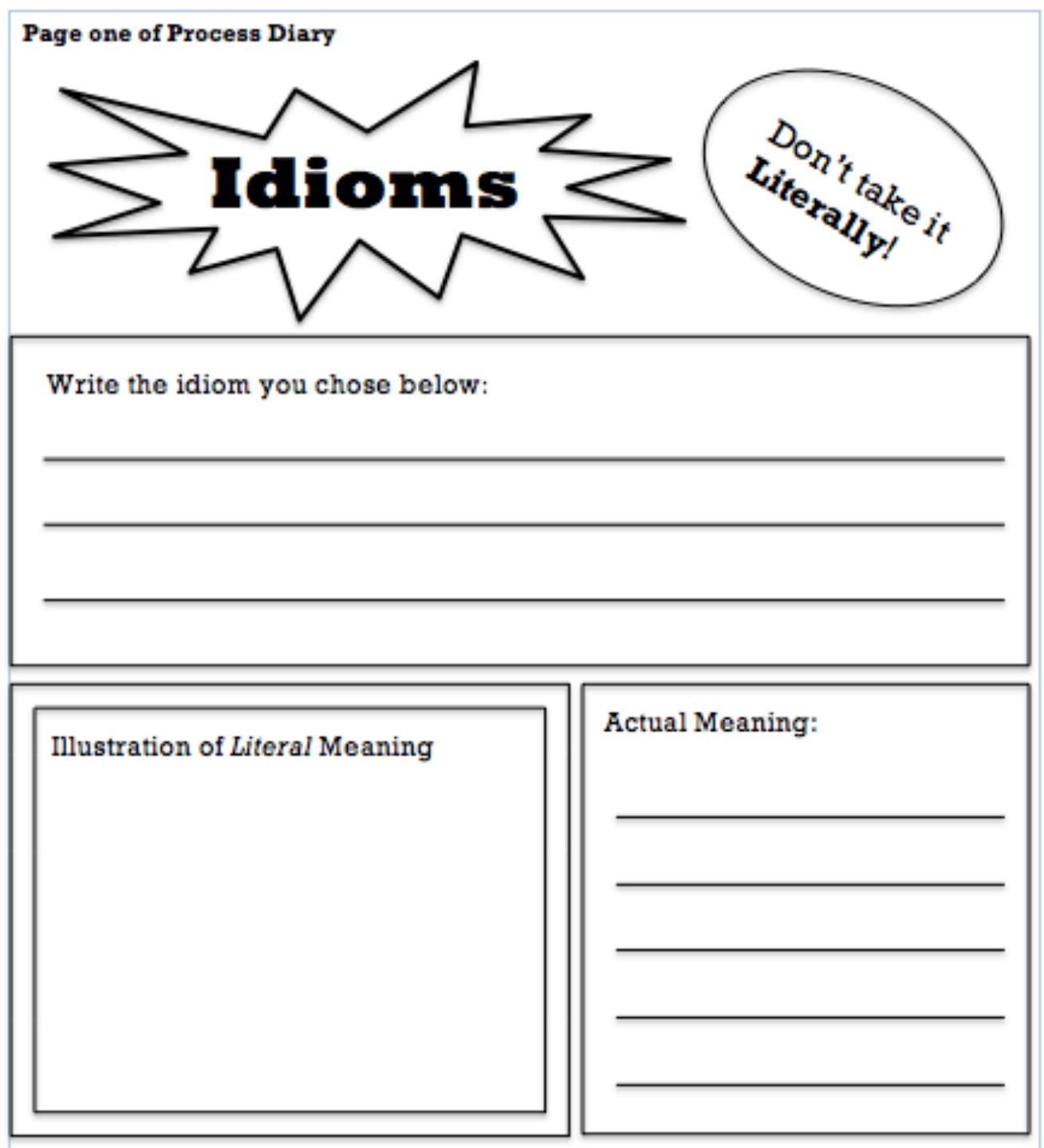

Use it in a sentence.

Figure C-2. Third page of idioms packet. 


\section{Page two of Process Diary}

How does your idiom relate to a personal memory?

Why is this memory important to you?

On page three of your process diary you will create two sketches of what you want your mask to look like. It will need to be a hybrid face and idiom. You do not need to represent the whole idiom but can choose part of it instead.

Think about color, texture, and proportions of the face.

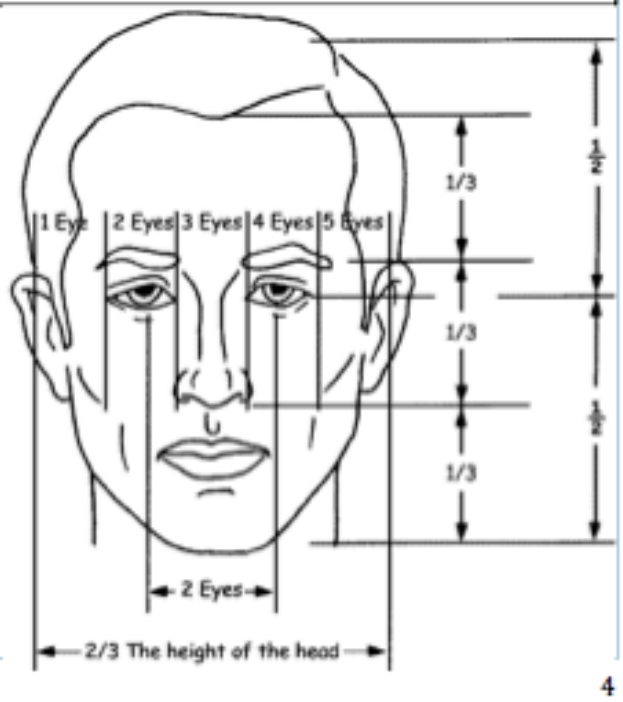

Figure C-3. Fourth page of idioms packet. 


\section{All About Clay!}

Fill in the correct clay terms:

1. - a textured mineral substance that is flexible when wet and can be hardened by firing. - a large, hot oven that is used to fire the clay. It can reach temperatures of 2500 degrees F. and higher. Your oven at home maybe reaches 500 degrees $F$.

3. -Making clay products permanent through heating to a required temperature in a kiln.

4.

-A coating of colored, opaque, or transparent material applied to ceramics after bisque firing to make the piece more permanent.

\section{Four Stages of Clay}

\section{Wet} (Plaskle):

Clay that is soft and easy to work with

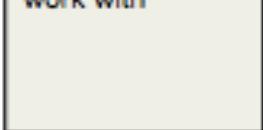

2. Leather
Hard: Unfired
clay that isn't
quite dry, yet firm
enough to carve

3.8one Dry
(Greenwerere:
Unfired clay that
is free of water
and ready to fire.

4. Bisque ware: Clay after it's first firing. At this stage it is more permanent and can be glazed or painted.

At what stage is the clay most fragile?

Figure C-4. Fifth page of idioms packet. 


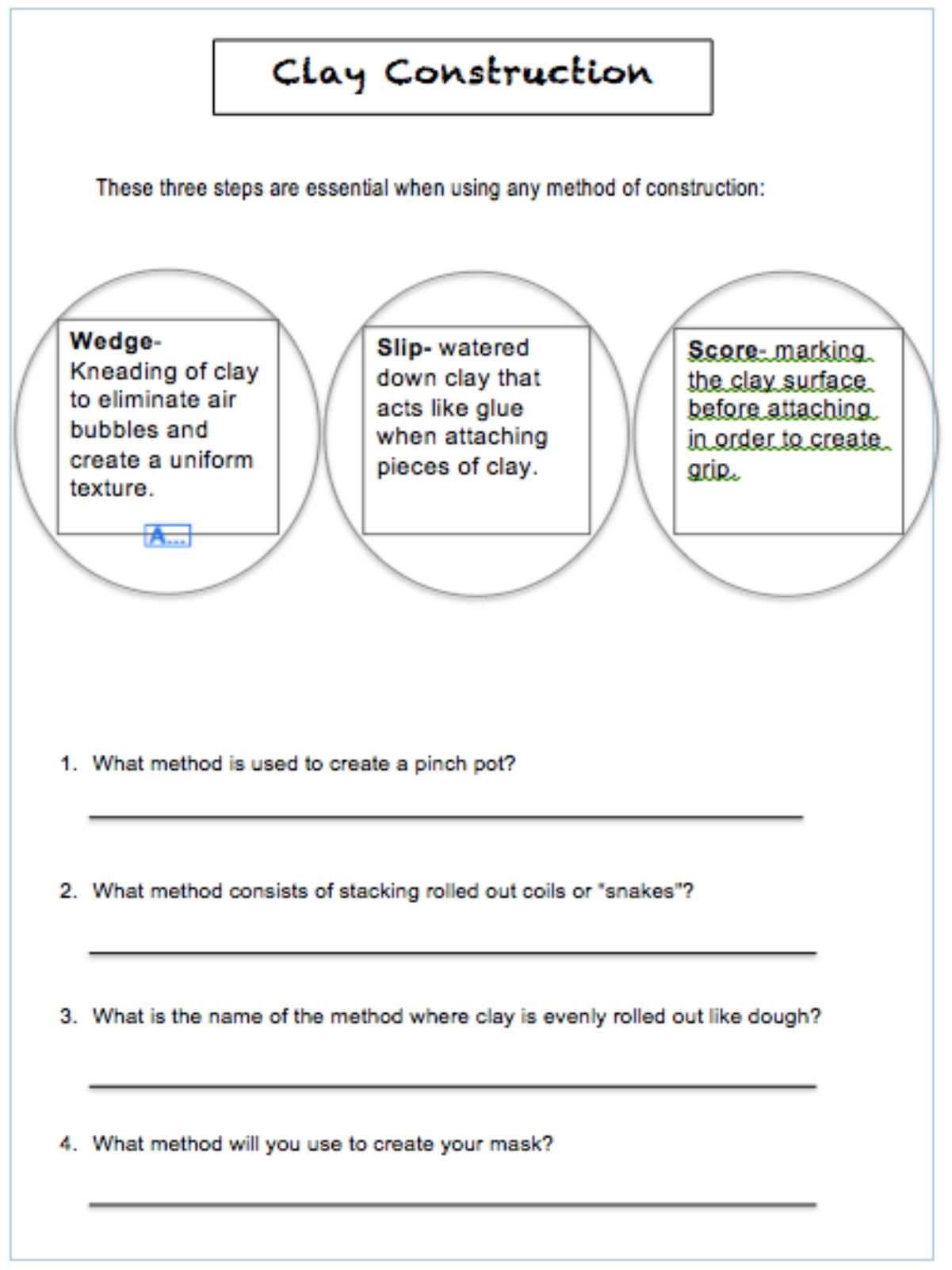

Figure C-5. Sixth page of idioms packet. 
APPENDIX D

STUDENT WORK

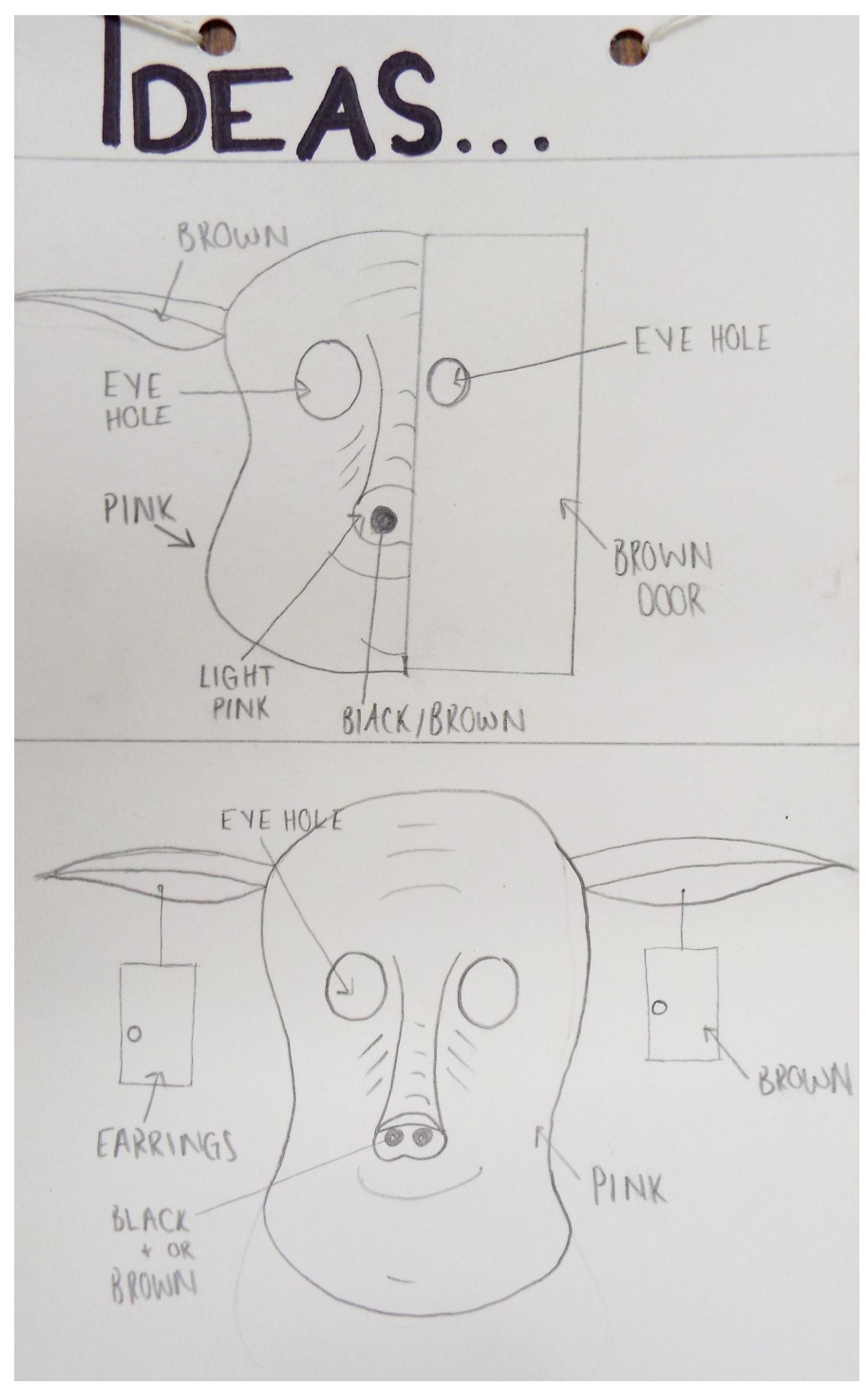

Figure $D-1$. Pig out. Final page of visual process diary. 


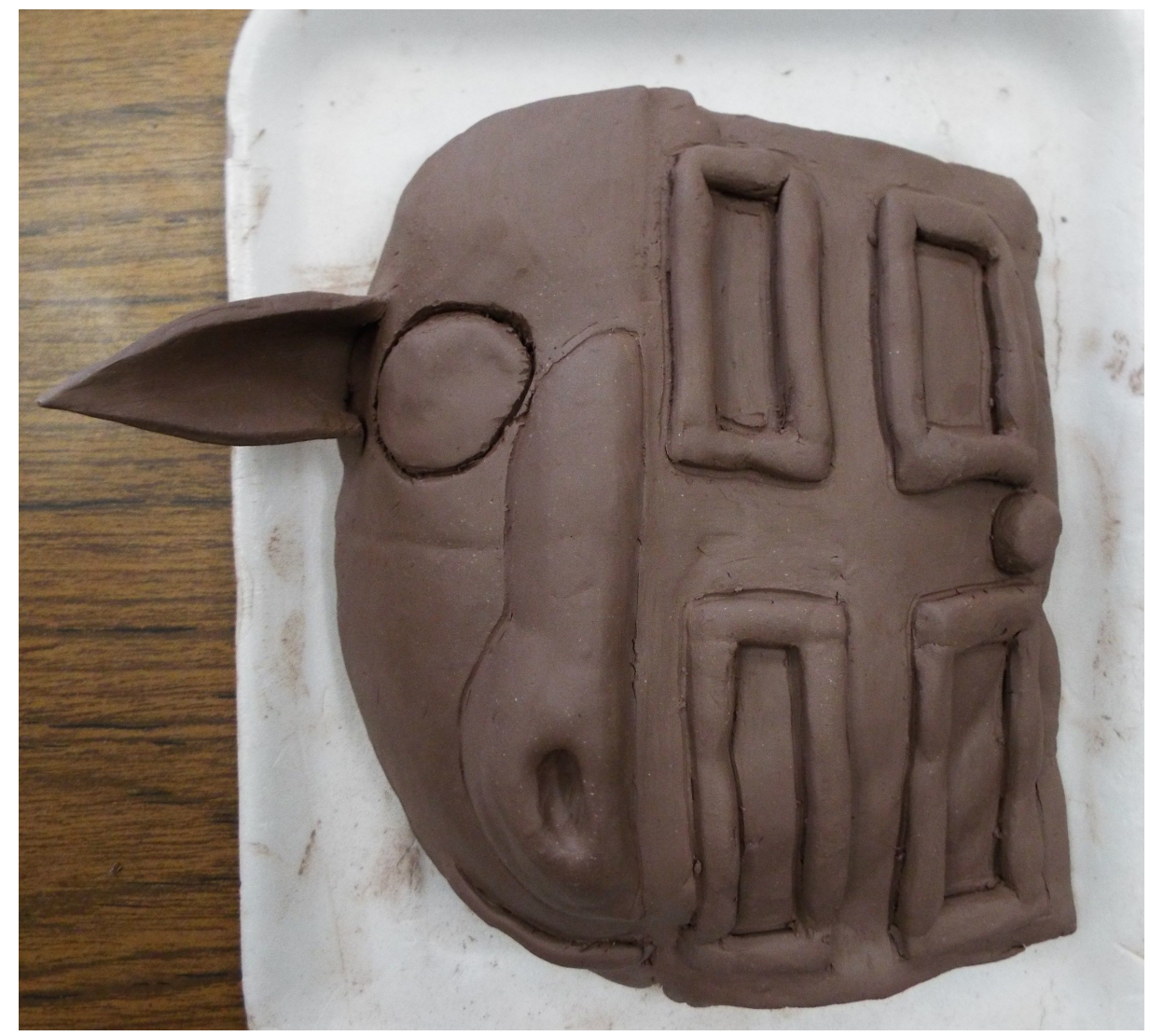

Figure D-2. Pig out. Mask. 


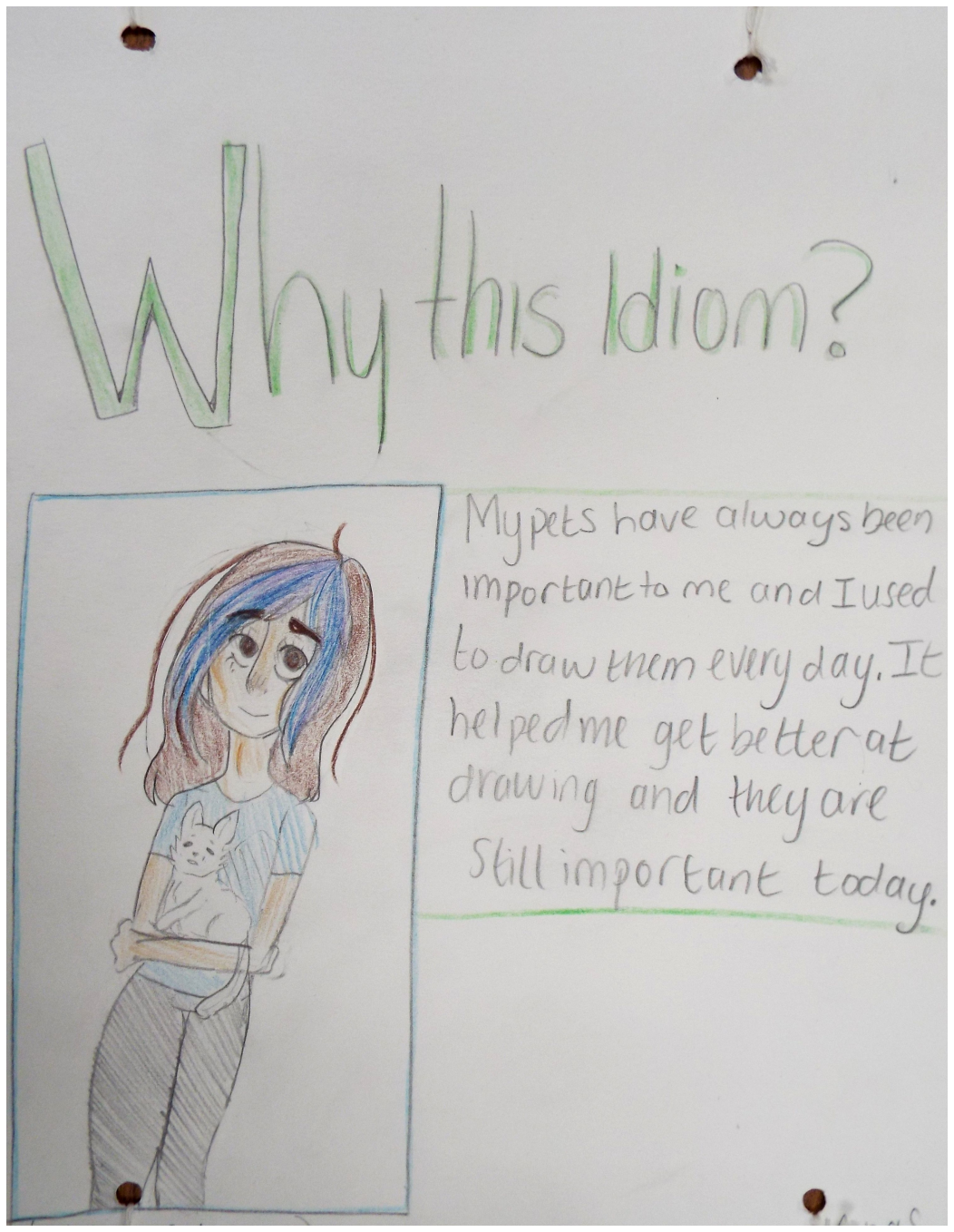

Figure $D-3$. Apple of my eye. Page one of visual process diary. 


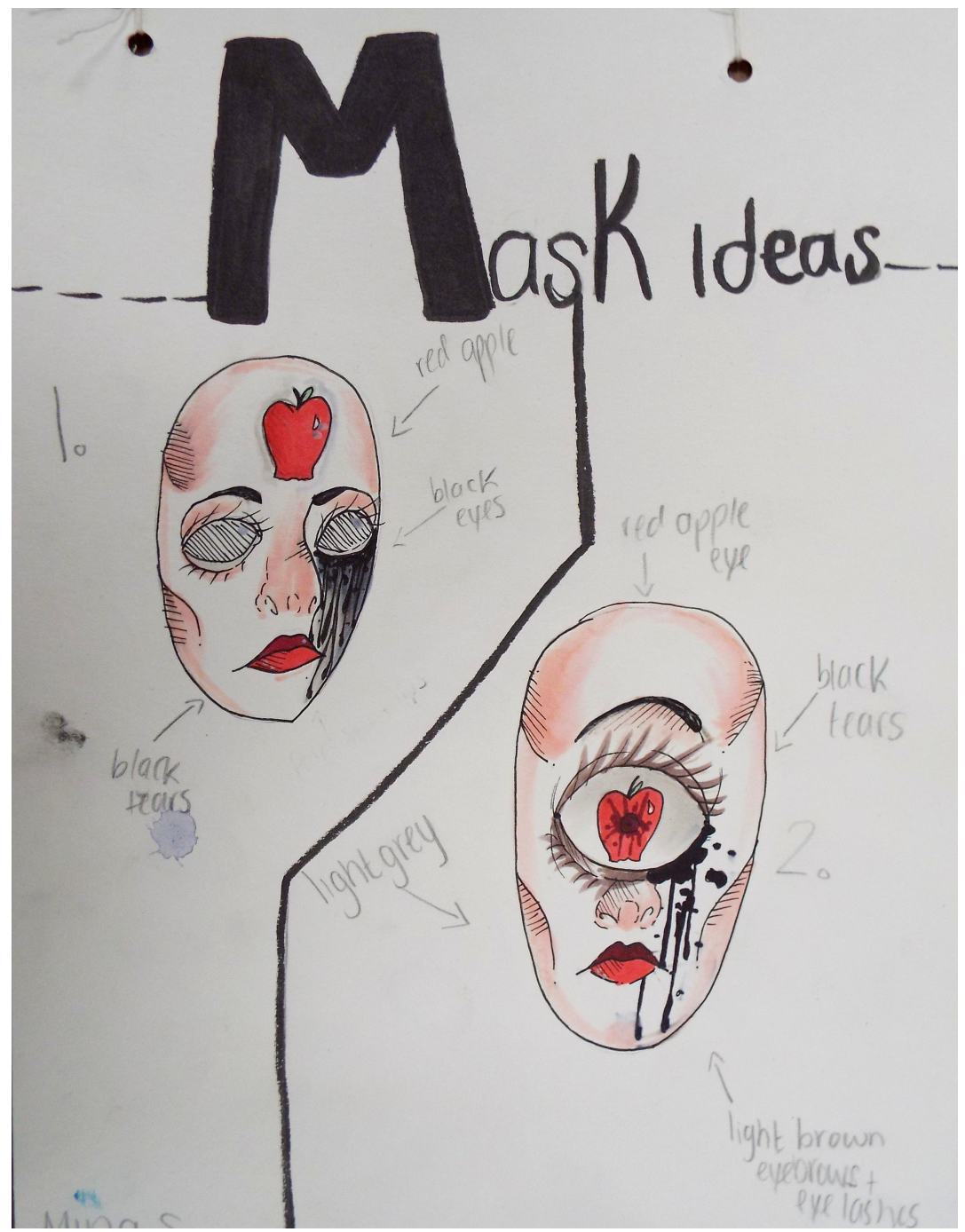

Figure D-4. Apple of my eye. Final page of visual process diary. 


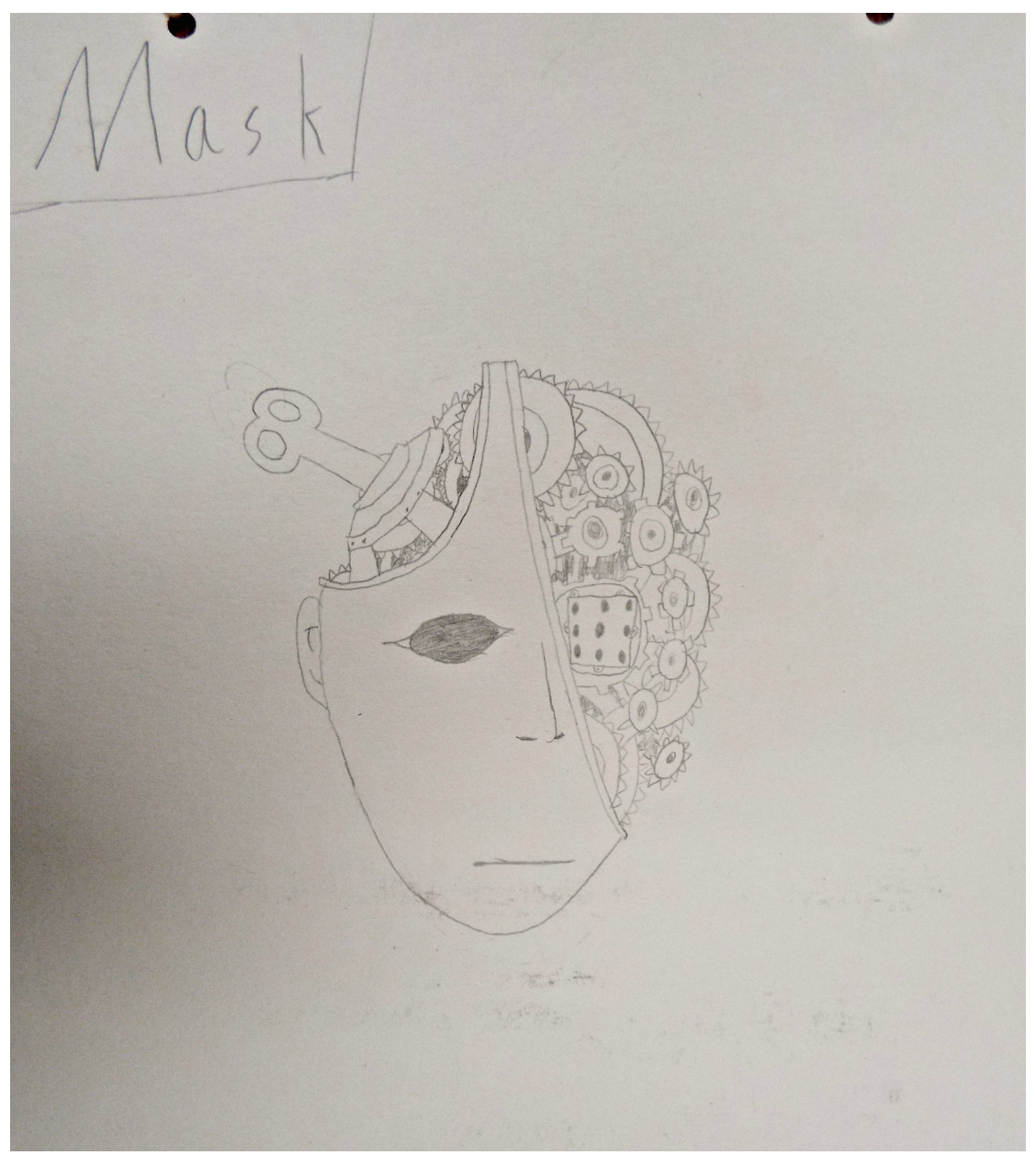

Figure D-5. Against the clock. Final page of visual process diary. 


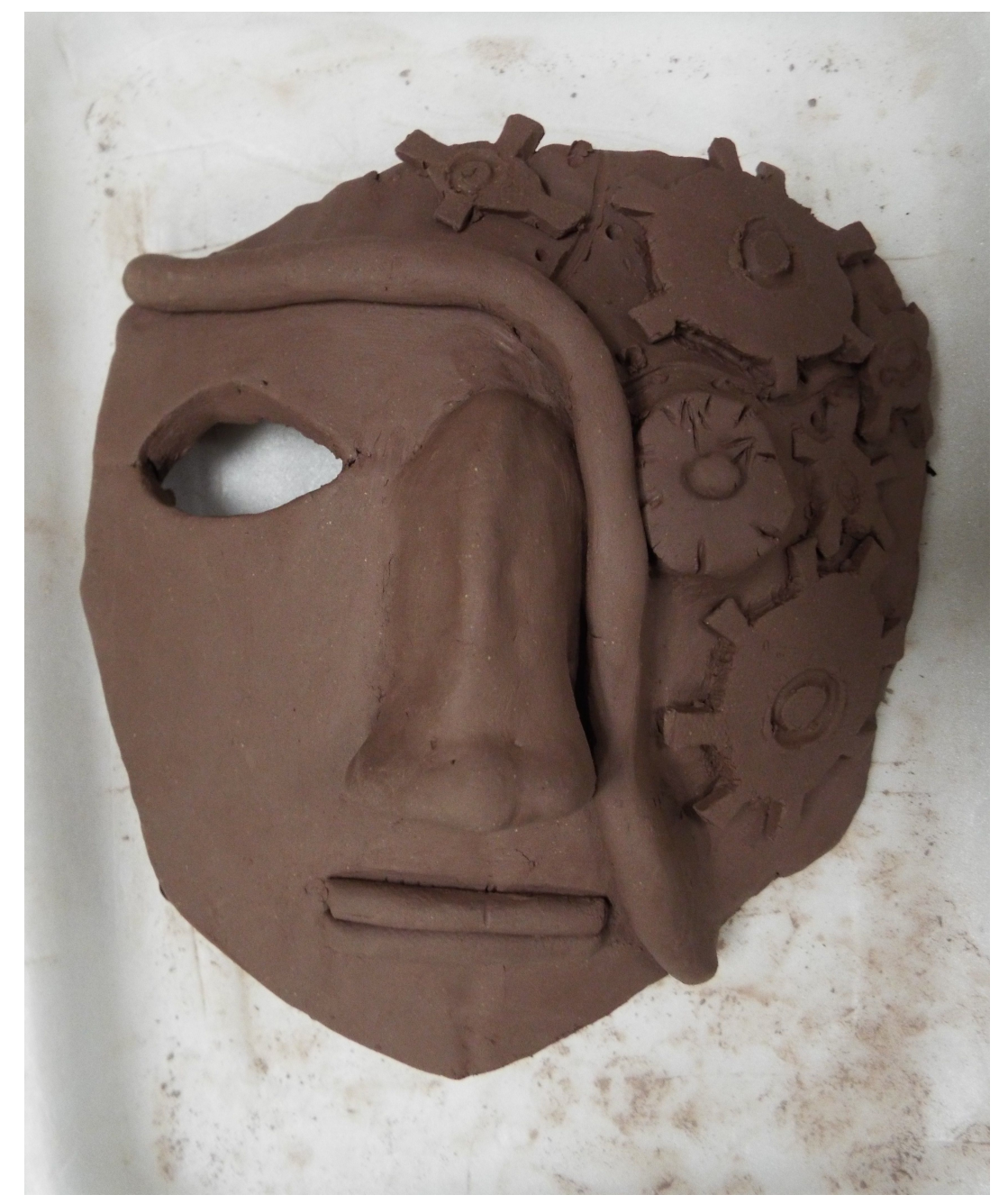

Figure D-6. Against the clock. Mask. 


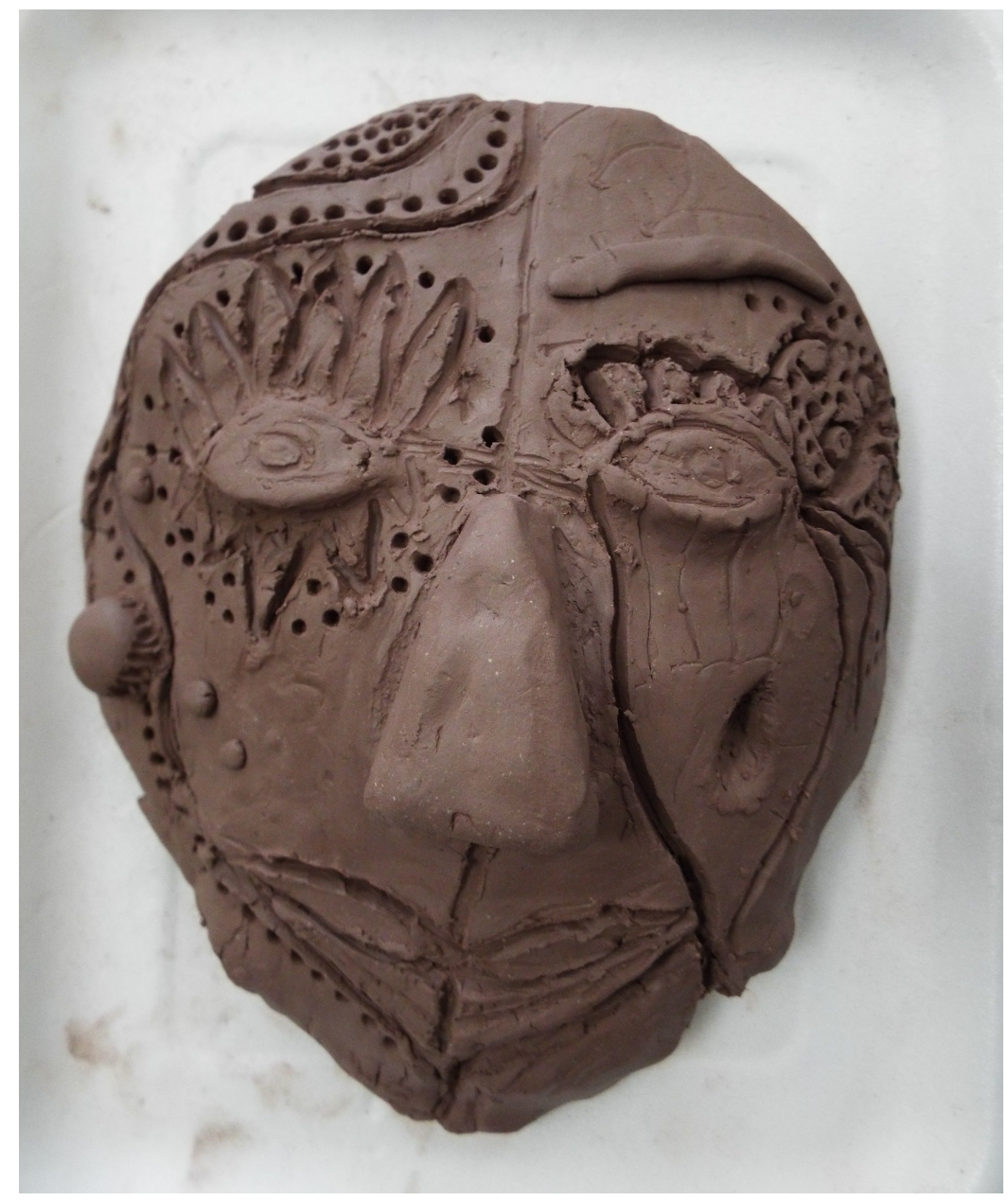

Figure D-7. Grass is always greener. Mask. 